U \& Dept of Aquaculture.

The Granular Venereal Drear and abortion in cattle leans. 


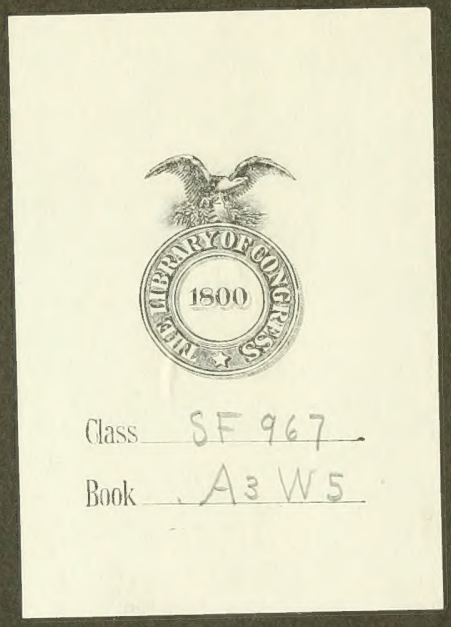




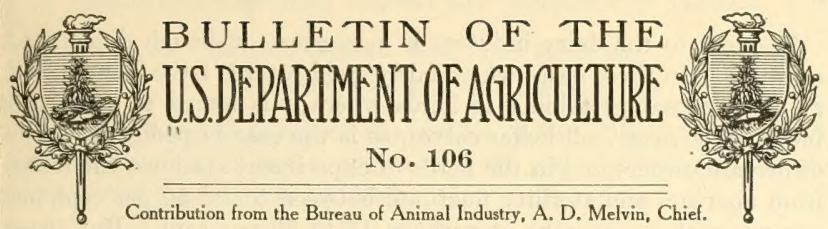

September 12, 1914.

(PROFESSIONAL PAPER.)

\section{THE GRANULAR VENEREAL DISEASE AND ABORTION IN CATTLE.}

By W. L. Wrulams, ${ }^{1}$ Professor of Surgery, Veterinary Department, Cornell University.

\section{INTRODUCTION.}

Early in 1909 the writer had publicly announced the existence in a dairy herd in New York of the granular venereal disease, nodular vaginitis, or vaginitis folliculorum chronica contagiosa. Later observations showed that it was general, if not universal, among the herds of the State. This disease having been held responsible by many continental European veterinarians of high authority for the abortion and sterility of cows, it was deemed important that first of all it should be determined how widely and extensively this malady exists among the cattle of the United States. In order to accomplish this, it was decided to make post-mortem observations upon the genitalia of cows, heifers, and haifer calves on the killing floors of abattoirs at some of the principal slaughtering centers. The inspectors in charge of the Federal meat inspection at these stations, under instructions from the Chief of the Bureau of Animal Industry, United States Department of Agriculture, cooperated most heartily, and a large volume of most interesting material was furnished in the most convenient manner possible for inspection.

The importance of abortion and sterility in cows is rapidly becoming more acutely felt by breeders, and is each year playing a more serious part in the national economy. By interfering more and more with the reproductive powers of cows, these diseases exert an unfavorable influence upon the production of meat, milk, and dairy products, decreasing the supply and increasing the cost.

\footnotetext{
- In conjunction with the Pathological Division, Bureau of Animal Industry, United States Department of Agriculture.

Note.-This bulletin describes a very common affection of breeding cattle, as to which there is a wide diversity of opinion. The paper is the result of extensive study, and is of interest to veterinarians and cattle raisers generally.
}

$43378^{\circ}-14-1 \quad$ Monograph 
The loss to the dairy industry is very great, although difficult to estimate. In those cases where fairly good records have been placed at our disposal pertaining to herds where it is aimed to raise and breed all or nearly all heifer calves, as is the case in pedigreed herds of private owners and in the herds of experiment stations, the losses from abortion and sterility fluctuate between 5 and 50 per cent per annum, with an average of perhaps 15 to 20 per cent. But these statistics are deceptive, and not safe for general deductions. These herds consist too largely of heifers, in which abortion and sterility are most common.

As nearly as we have been able to estimate, an estimate which is admittedly insecure, the annual losses in the dairies of New York from abortion and sterility are approximately 10 per cent, which probably exceeds $\$ 5$ per cow for the total number in the State, or an approximate economic loss of perhaps $\$ 10,000,000$ annually. Our inquiries regarding losses in other States, in beef as well as in dairy herds, indicate that there are no material differences in the ratio of losses in the various regions.

Innumerable reasons have been assigned to account for abortion and sterility in cows. Abortion has been regarded as the result of blows, goring, kicks, slips, falls, various feeds, waters, drugs, etc., and finally, when the abortions are numerous, to contagion. Sterility has been attributed also to a great variety of causes - to the character of the feed or water, to poverty, and overfatness, and, as with abortion, when the cases are numerous, to contagion.

Veterinarians who have investigated abortion in cows in recent years have agreed that in a very large percentage of cases it is due solely to contagion. The British Royal Commission for the investigation of this malady believes that more than 90 per cent of the abortions among cows in England are due to contagion, while Bang in Denmark, Hess and Zschokke in Switzerland, and other veterinarians of Europe hold similar.views. Similar views are also held regarding sterility in cows by Hess of Switzerland, Albrechtsen of Denmark, and other leading investigators.

The basis of diagnosis relied upon in this report for determining the presence or absence of the granular venereal disease was the visible presence or absence in the mucosa of the vulva of the granular or nodular elevations generally regarded as a result of the infection. The number or size of the nodules visible to the naked eye was not taken into account as determining whether the animal was affected or not. If the nodules were visibly present the animal was classed as affected; if nodules were absent or were not to be detected the animal was marked negative or free.

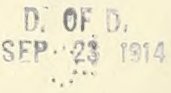


THE GRANULAR VENEREAL DISEASE.

DISTRIBUTION AND PREVALENCE.

Table 1 presents concisely the results of the observations regarding the distribution and prevalence of the granular venereal disease throughout the territory covered.

TABLE 1.-Prevalence and geographical distribution of the granular venereal disease in cattle.

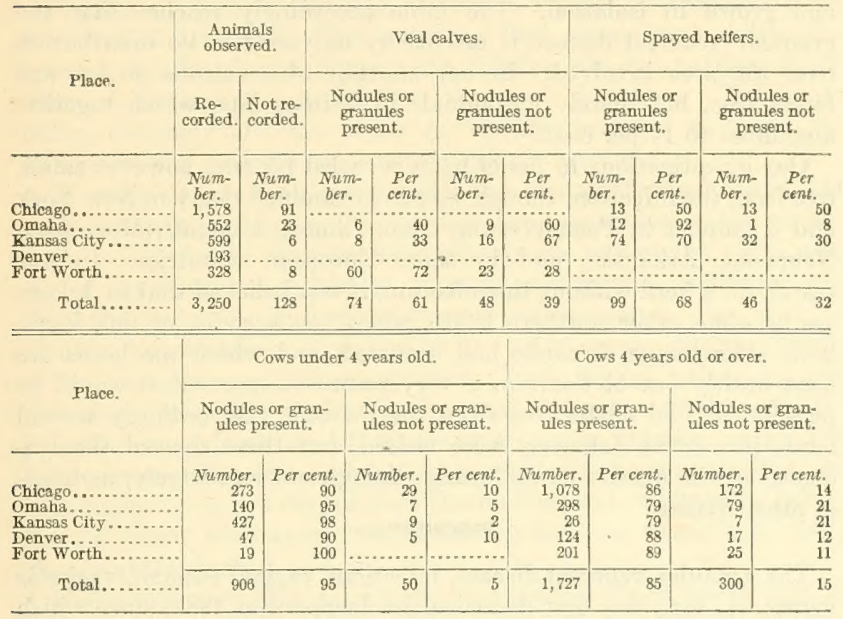

Table 1 shows a total of 2,806 cases where nodules or granules in the vulvar mucosa were macroscopically visible, as against 444 cases where they were not visible. This makes the average visible infection in all classes of animals 86 per cent.

Viewing the malady as one fundamentally venereal in character, though readily and abundantly transmitted otherwise, we observe the lowest ratio of infection, 61 per cent, in heifer calves slaughtered for veal and ranging between 6 weeks and 1 year in age, presumably because they had not copulated and hence had escaped the basic mode of infection. The next lowest ratio of infection, 68 per cent, is that of spayed heifers, where again, when spaying had been properly done, copulation was excluded as a factor in transmission. In the next class, comprising entire females from 1 to 4 years of age, essentially all of which had presumably been bred, the number of affected advances to 95 per cent, to fall again to 85 per cent in cows over 4 years of age. 
The average percentage of infection in the slaughtered animals, as shown in this table, is lower than observed generally in herds in New York and other States. The observations here recorded were largely upon cattle of the beef breeds, which are not regularly kept in as close contact as dairy animals. In Chicago there were, however, a considerable number of dairy cows. In dairy animals it is rare to find, at least in the State of New York, a heifer calf 3 months old without the malady, except she has been early removed from her dam and grown in isolation. The table accordingly teaches that the granular venereal disease is essentially universal in its distribution over the area involved. In our abattoir observations no lot was found free, but merely individuals in various lots, which together amounted to 14 per cent.

Our investigations in herds have revealed no one, however small, free from the infection, though we have examined many in New York and a number in Pennsylvania, Ohio, Illinois, Missouri, Minnesota, Nebraska, Arkansas, and in some European countries. In our search for a herd without the infection, it was believed that in Arkansas or some other southern State, where, on account of tick fever, little interchange of cattle had occurred, and where the herds are kept mostly out of doors in a very primitive manner, it would be possible to find cattle free from the malady. Accordingly several herds in central Arkansas were visited, but these showed the evidences of the disease as uniformly, though not as severely, as herds in other States.

\section{DESCRIPTION.}

The granular venereal disease, infectious vaginal catarrh, vaginitis verrucosa, etc., was first described by Isepponi in 1887, since which time it has been recognized and investigated by a great number of writers, chiefly in Switzerland at first, then in Austria, Germany, France, and other continental European countries.

When or where the disease began no one knows. It has been stated by numerous writers that the disease has spread during recent years over a province or community or from one region to another, but this recorded spreading of the malady may well be accepted with caution. A knowledge of the existence or the recognition of the presence of a disease may circulate in such a manner as to become confused with the extension of the malady itself, and this is unquestionably true in a large measure of the granular venereal disease. We may well say that this disease is the most universal infection known in any species of domestic animal.

The granular venereal disease may be defined as a chronic infection of the genital tract of cattle, expressing itself clinically in the form of granular or nodular elevations in the genital mucosa, chiefly of the vulva, less frequently of the vagina. 


\section{SYMPTOMS.}

The essential clinical symptom of the granular venereal disease consists of the appearance in the vulvar mucosa, protruding above its surface, of nodular, conical, spheroidal, or flat elevations, usually 1 to 2 millimeters in diameter. They are best observed clinically by holding the vulvar lips apart and causing a strong light to enter the vulva obliquely. The examination may be conducted advantageously in a well-lighted stable, by having the animal placed with her posterior parts presenting toward a window somewhat above the level of her back. The examiner then grasps each vulvar lip between the thumb and fingers, and, drawing the lips backward and outward, exposes the interior of the vulva to vision. The light, falling obliquely into the vulvar cavity illuminates it well, and, by refraction, the nodules are brought clearly into view.

In order to examine every part, the examiner should shift his position again and again, that he may view such area at the proper angle. In order to examine satisfactorily the roof of the vulva, the eye of the examiner should be on an approximately horizontal line with the mucosa. Highly satisfactory examinations may also be made in dark stables or at night with the aid of a good reflecting lamp.

The nodules are also recognizable upon digital palpation, the elevations being very evident to the sense of touch. At times digital palpation may have an advantage over vision because, as related below, even when the nodules are abundant, the mucosa may be edematous to such a degree that the nodules are rendered invisible, the thickened, edematous mucosa serving to cover them from view, though still palpable.

Under the prevailing conditions in American dairy herds, and so far as we know in the dairy herds of the world, heifer calves usually develop clinical signs of the disease at from 4 to 12 weeks of age, and from that time through adult life to old age present a series of interesting vacillations of intensity so great that various writers have designated these manifestations as acute, subacute, chronic, cured, sound, etc.

If the newborn heifer calf is kept in the same stable with dairy cows, perhaps in contact for two or three days with her dam, is fed and handled by persons who are in close contact with the cows, and placed in a common inclosure with older infected calves, the vulvar mucosa usually appears normal, smooth, moist, pale rose-colored for a period varying from 4 to 12 weeks, or even longer, when visual inspection reveals the presence of several or many spheroidoconical nodules in the vulvar mucosa 1 to 2 millimeters in diameter. They are usually solitary until they become very numerous, when they tend to become arranged in rows. They are most frequently colorless or faintly yellowish in the center and present the appearance of small, tense vesicles, but upon close examination they are 
hard to the touch and contain no fluid. Encircling the base of each nodule there usually appears a pale or bright vascular area, apparently due to increased vascularity (which a histological examination proves correct), thus giving the lesion the appearance of a minute vesicle surrounded by a vascular girdle. The nodules are scattered here and there, frequently along the floor of the vulva in the clitoral region, but quite as often on the sides or the roof of the vulva. Except for the nodules and the vascular girdle about the base of each, the surface of the mucosa in the early stage is smooth, pale rose-colored, and normal. There is no swelling, no inflammation, no discoloration of the vulvar mucosa, and no mucous or muco-purulent discharge.

Slowly and insidiously the disease spreads to individuals which have hitherto escaped, so that the older the heifers in a herd the larger the percentage which shows the evidences of the disease. The rapidity and uniformity in the spread of the malady rests largely upon environment. In the closely housed and much-handled heifer calves in dairies usually more than 90 per cent show the disease at 4 months of age, and before they reach one year the visible infection generally reaches 100 per cent, but if by any chance an individual escapes infection until breeding age the first service by the bull conveys the disease. In heifer calves not kept in close or prolonged contact with their dams or with older infected heifers, and not much if at all handled by persons who are habitually in contact with diseased animals, the infection spreads much more slowly. Thus we have observed in a herd of padigreed Herefords approximately but 50 per cent of infection in virgin heifers and heifer calves. After birth these calves were allowed to go with their dams for a day or two and were then permitted to suck twice daily, but otherwise were kept separate from their dams or other older cattle.

In experimental heifer calves we have kept individuals up to 6 months, and even to one year old, without any trace of the infection.

The influence of environment upon the spread of the infection in heifer calves is further exemplified by Table 1, wherein the 122 veal heifers observed showed an average infection of 61 per cent. The percentage of infection among these calves is markedly below the average infection among heifer calves in eastern dairy herds of corresponding ages. Western veal calves largely run at liberty in the open, exposed to the infection from their dams but not from personal handling or close crowding in stables.

The number of the nodules generally increases slowly with the age of the virgin heifer from the date of infection up to puberty or estrum, when the increased vascularity and functional activity of the genital tract apparently favors a more rapid multiplication of the nodules and intensifies generally the symptoms of the malady, but these in the virgin heifer rarely if ever attain that intensity commonly seen after copulation. 
When the nodules have become quite numerous they tend to become arranged in longitudinal, parallel rows corresponding to the longitudinal folds of the vulvar mucosa, the nodules being located upon the summits of the rugæ, emphasized and rendered more distinct by the inflammation of the mucosa, which causes it to swell, harden, and thicken, and forces it into marked folds. The individual nodules change in appearance. They increase little in size and projection. The vascular areas about their bases become more deeply injected and the vascularity may extend more or less completely over the surface of the nodules, so that some of them appear as bright-red elevations or as petechiæ on the vulvar mucosa.

The mucosa itself, between the nodules, becomes involved in the disease, is injected, red, and swollen. With the advent of definite irritation of the vulvar mucosa, a slight muco-purulent vulvar discharge ensues. It is not at first marked. Many say it is not present, or rather that the discharge noted is normal. There is, however, a visible discharge which so mats together the vulvar tuft and surrounding hairs in the heifer calf that in opening the vulva for inspection the examiner must frequently break down the adhesions between the surrounding hairs before the vulvar lips may be parted. Some contend that this is normal, but in experiment heifer calves observed by us such vulvar discharge has not appeared until infection had ensued. Herbivorous females of other species do not ordinarily present muco-purulent or other vulvar discharges. It would accordingly appear that mucous secretions normally occurring in the genital tube of heifer calves, heifers, and cows should be disposed of by the organs in a manner which would prevent their becoming conspicuous externally.

Up to the date of puberty or estrum the nodular venereal disease of heifer calves generally behaves essentially as a dormant malady, without material significance for the immediate welfare of the animal. Various observers may and do hold divergent views. Numerous cases are viewed by many veterinarians as sound because of the mildness of the symptoms, but the nodules are there, and so long as these are admitted as the deciding lesion of the malady the heifer must be regarded as infected.

Copulation is the signal for the awakening of the dormant infection, which behaves like other venereal disorders in animals and man under the stimulus of sexual contact. Within 24 hours after copulation the evidences of sexual irritation are marked. The mucosa becomes scarlet, swollen, tender, and in a large proportion of cases there is a very notable muco-purulent discharge which adheres to the vulvar tuft and soils the under surface of the tail and the skin of the buttocks and the perineum.

The vulvar lips frequently become markedly swollen and edematous. If the vulvar lips be parted, the vulvar mucosa is seen to be 
covered with masses of stringy, semiopaque mucus, or there may be seen small opaque flakes of muco-pus resting upon the mucosa.

The nodules now multiply with astonishing rapidity. Their arrangement in parallel longitudinal rows becomes well marked, the nodules being crowded into close contact with each other upon the summits of the swollen, hypertrophied mucous rugæ. The nodules frequently lose their transparency and assume a deep-red color, and the malady assumes in every way a more decisive clinical aspect of important disease. Even then, however, it is not noticeable in so far as the general health of the heifer is concerned.

The intensity of the symptoms increases for a few days, remains static for a time, and then tends to recede slightly, but the betterment makes no appreciable approach to the status which had been maintained prior to copulation-a fact which emphasizes strongly its essentially venereal character.

Should the heifer become pregnant at the first service, the irritation may abate slightly and slowly for a time, but the nodules remain prominent and approximately as numerous as ever, and the clinical evidences of disease remain essentially static, at one period apparently improved, at another worse, until near the time for parturition, when the vulvar mucosa becomes more reddened. A marked edema (parturient edema) then appears, the nodules are covered over and are no longer visible. Usually they may still be felt upon careful palpation. In many cases of abortion the edema of the vulvar mucosa is essentially the same as if parturition had occurred. Should parturition or abortion be followed by retained placenta and chronic metritis or pyometra, the nodules continue masked by the persisting edema so long as serious uterine disease continues. Otherwise, with the gradual disappearance of the edema of the mucosa the nodules slowly come again into view.

If the heifer fails to conceive at the first copulation, when the next estrual period arrives and copulation occurs, should the sterility be refractory, the symptoms tend to increase, so that sterile heifers are quite generally among the worst clinical cases of the disease in a herd. The symptoms of the disease retain approximately the average intensity acquired during the first pregnancy through the second and third pregnancies, when the severity of the malady gradually abates.

When the cow reaches 8 to 9 years of age, and her sixth or seventh pregnancy, the decrease in the intensity of the disease generally becomes quite marked, the nodules are fewer, less prominent, and more transparent, the irritation and injection of the raginal mucosa is definitely decreased, and the muco-purulent discharge has largely abated. With advancing age, the vulvar mueosa becomes pale yellowish, or bluish-yellow, the nodules disappear, and the clinical evidences of the disease commonly vanish when the cow has reached the age of 12 to 15 years. 
Such is a brief outline of the course of the malady as observed in a majority of cases, but the course is vacillating aud erratic in individuals and in herds. Copulation always intensifies the symptoms, and one can generally identify by clinical examuation nearly all cows recently bred.

The use of antiseptics in the rulro-raginal tract alters the clinical appearances profoundly. Daily washing of the ragina with nonirritant warm antiseptic solutions causes the symptoms of the malady to decrease rapidly in intensity, and in a few weeks the nodules may almost whully disappear, the mucosa becomes smoother and softer, the color changes to a pale rose-red, and it looks as if the continuance of the handling would soon eliminate the disease, but in the end some nodules remain, and with a cessation of handling unaccompanied by copulation the symptoms remainstatic. On the other hand, when powerful antiseptics are introduced into the ragina the mucosa becomes irritated, swollen, and edematous, and the nodules become reiled.

Thus the clinical signs of the malady appear insidiously, usually when the heifer is but a few weeks old; the disease then pursues a comparatively uneventful course up to breeding age, then becomes suddenly intensified, and quickly reaches its zenith, where it maintains, with certain vacillations, an approximately horizontal course for three or four years, when it begins to abate slowly in intensity, to more or less completely disappear clinically with the adrent of old age.

TABLE 2.-Influence of pregnancy and other conditions upon the visibitity of the granular venercal disease.

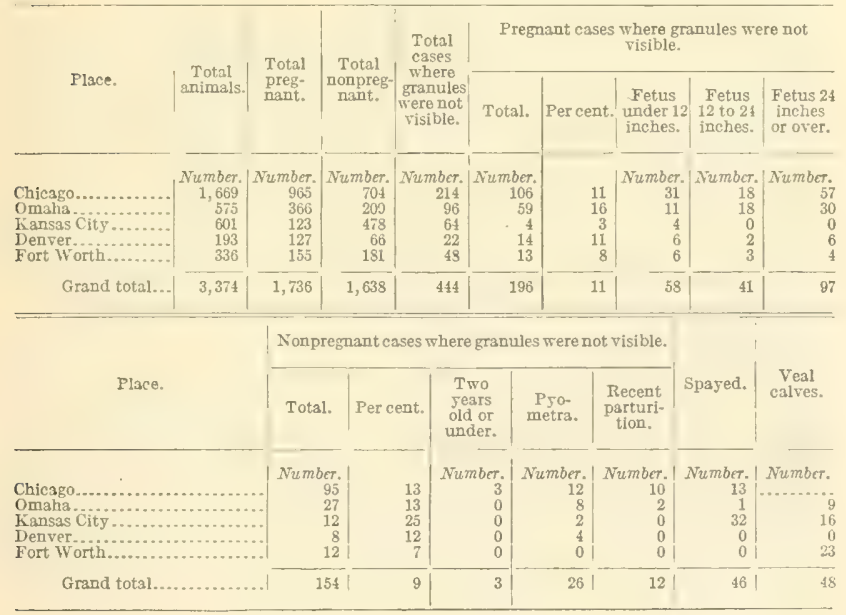


$\Lambda$ study of Table 2 illustrates some of the influenees which modify the visual signs of the malady. Among the pregnant animals in which the granules were not apparent macroscopically, the fetus exceeded 24 inches in length in about 50 per cent of the cases, while in the earlier stages of pregnancy the granules were more generally present. Among nonpregnant females the influence of pyometra and recent parturition is very marked.

Table 1 shows that many young heifers sold as veals escape the infection, while spayed heifers, usually free upon the range, quite generally escape. But the tables tell only a part. It was a very notable phenomenon that the probability of both the presence and intensity of the disease rested vary largely upon the question of copulation.

The spaying of range heifers is not generally well done. Thooperition is rery carelessly and hastily performed, usually by the flank method, the operator thrusting his hand through the wound, grasping the oraries and stripping them from the broad ligament between the thumb and fingers. The result is that 50 to 60 per cent of them are only partly spayed, some orarian tissues are left which derelop orisates and eysts, the heifers come in estrum or are nymphomaniac, and copulate freely with range bulls. The lesions of the granular venereal disease are uniformly seen in such imperfectly spayed animals, and show considerable intensity. In the perfectly spayed heifers the vulvar mucosa is generally normal, smooth, and pale rose-red, with but few if any visible nodules.

Another striking illustration of the influence of coitus upon the intensity of the disease was observed in a lot of 270 two-year-old range IIereford heifers which had evidently been kept away from the bull, except in the case of one individual which had, perhaps accidentally, become pregnant. In the 269 nonpregnant animals the disease was quite uniformly present, but only a few nodules were seen in each individual. Careful inspection was required lest they be passed over. The vulvar mucosa of the one pregnant heifer, however, bore more of the granules than the other 269 collectively. The entire mucosa was swollen and red, and dense masses of granules crowded thickly upon each other.

Throughout its long course the intensity of the infection rises aud falls, sometimes in obedience to known causes, as copulation, sometimes in a manner not yet understood. During the period at which the disease is at its zenith fow animals fail to show the elinical evidences of its presence, as is shown by Table 1 , according to which the evidences of the disease were apparent in 95 per cent of cases. This is no higher than regularly observed at this age in dairy herels. 


\section{HISTOLOGY.}

The histology of the disease has not been extensirely studied. Isepponi speaks of the nodular elovations as granuloma; Ostertag views them as swellings of the lymph follicles normally present in the vulvar mucosa, and Martens also regards them as swellings or hypertrophy of normal papillary bodies.

Thoms has investigated the histology of the malady most fully. As a basis for his study of the normal vulvar mucosa ho selectod a cow about 7 years old and a calf 10 weeks old. The normality of the mucosa of these two animals may well be questioned. While in Table 1 there has been recorded a total of 300 cows over 4 years old in which nodules were not recognized, I would be wholly unwilling to select one of these as sound. The examination was merely negative as to their presence, not positive as to their absence. Thoms concludes that animals of any age may be infected, that with an exudate bearing the diplococci and short streptococci the disease may be induced experimentally in 16 hours by inoculation, that in four or five days nodules appear which consist mostly of the hypertrophy of the existing papillie in the vulvar mucosa, but are largely the result of the formation of ontirely new follicles by the accumulation of round cells in clumps, and that after healing the follicles atrophy gradually, but fail to return completely to their former size. Hence he concludes recovery is not wholly dependent upon the resumption by the follicles of their normal size.

\section{BACTERIOLOGY.}

The bacteriology of the granular venereal disease has been but little studied, and the conclusions reached may well be modified by future investigations. Ostertag concludes that the disease is due to a diplococcus or short streptococcus, which he recognized in the muco-purulent exudate in the ragina and rulva, and in ope case in the uterus. He introduced the organism into the ragine of cows, shcep, goats, swine, and horses, causing in cows a chronic purulent vacinal eatarrh, which agreed perfectly in its symptoms and course with catarrhal vaginitis, and from the diseased exudates of these animals pure cultures of the streptococcus were recovered. In sheep, goats, swine, horses, guinea pigs, and rabbits the results were negative.

In investigating the granular venereal disease we need as a basis an animal with unquestionably sound genital mucosa. This Ostertag believes he has secured. Details of the basis upon which he declares them sound are wanting. So with the transmission experiments of Ostertag. Were tho animals to which he believed he transmitted the affection actually and wholly free from the disease 
at the beginning of his experiments? There is every reason to believe that a calf in passing through the infected birth canal of its dam may become infected at the time of birth, or if not then it surely often becomes infected within a few days when kept in the same stall or stable or fed and handled by persons who come in contact with the diseased mother. If a new-born calf be removed from its dam at once and kept in strict isolation, I find that it will possibly escape infection for a time, but not probably, and that it will be several weeks before the macroscopic lesions appear.

Further and more serious doubt is thrown upon the recorded experiments of Ostertag in the symptoms and course of the experimental granular venereal disease from the fact that the recorded symptoms are in conflict with the present writer's clinical experienco with the beginnings of the disease. This has been gained by obserring hundreds of heifer calves from 2 to 6 months old affected with the disease, as well as a number of experimental calves under immediate observation, which must necessarily have evideneed the disease over and over again in its incipiency.

Ostertag says:

The first symptoms of infectious catarrh are swelling of the vulva, redness, swelling and sencitiveness of the vaginal mucosa, and a muco-purulent deposit upon the vaginal mucosa.

In the earlier stages of the malady, as wo have observed it, there are present none of the symptoms emphasized by Ostertag. On the contrary, the discase comes on insidiously, and the first sign of the malady is the appearance of a few nodules in the rulvar mucosa, sharply defined abore the surrounding epithelium, as pale yellow or colorless transparent elevations having a vascular girdle about their bases. Some would call these heifer calves sound, but if two or threo typical nodules do not indicate granular venereal disease it would be difficult to understand by what line of reasoning 200 or 300 nodules can assure us of the existence of the malady.

In other words, Ostertag describes, not the beginning of the disease, but an "explosion" of the existing malady under profound irritation. It is not strange that virulent streptococci induced the symptoms he describes, nor that he was able to recorer pure cult ures of the microorganisn from his experimental animals, but he has failed to reproduce the insidious, exceedingly mild early stages of the disease, which anyone who cares to do so may watch in heifer calves in any dairy. Neither need anyone fail to find cases, especially in recently bred heifers or young cows, in which all the symptoms described by Ostertag are present in their most impressire form, but that is not the beginning or end of the malady; it is its zenith. In a mucopurulent vaginal discharge streptococci are usually present, and, if sufficiontly firulent cultures are introduced into the vagina of an 
animal of the same species from which the culture was procured there need be little surprise if it cause irritation. Ostertig states that the raginal discharge comes from the formation of nodules and that the discharge is at first purulent or muco-purulent.

The granular venereal disease does not behare clinically liko a malady dependent upon streptococci or other pyogenic organisms. It is not fundamentally pyogenic. The inrestigations of Thoms and others have failed to show the formation of papules, ulcers, or neerosis of tissues. The granules or nodules do not suppurate. When the granules become highly numerous, the rulro-raginal mucosa is swollen and rough, the rugge overlap and strike against each other, the epithelium at the apices of the granules becomes abraded by compression and attrition, and, as Thoms relates, the result is a partial denudation of the epithelium, naturally leading to streptococcic infection and catarrh.

The granules behave unlike the product of streptococcic infection in their appearance and disappearance. They arise too suddenly and with too slight signs of irritation. In the heifer ealf they appear as transparent or translucent granules or nodules, the body of the granule showing little or no color, while the base has a yellowish or red girdle or areola. They are not obserred to grow. One day they are unseen, the next they are full size. In their mode of disappearance they behave very similarly. Their disuppearance is chiefly noted numerically and not by volume.

\section{PROGNOSIS.}

If we omit from our consideration such alleged consequenees of the nodular renereal disease as abortion, retained placenta, cystic degeneration of the ovaries, pyometra, and other serious affections of the genital organs, the prognosis as to the life of the patient is excellent, and the prospect for the amelioration and repression of the malady is highly favorable. But tho outlook for recovery, in the present state of our knowledge, is very poor, if not hopeless. There is necessarily quite as wide variation in the prognosis as there is concerning the essential symptoms and diagnosis. If one holds, as many do, that the disease is present only when the nodules are very numerous (each party haring his own conception of that definition) and there is a marked muco-purulent raginal discharge (the degree of which each must define for himself) and these conditions shall be accompanied by sterility and abortion, the prognosis may be good. With such a conception, howerer, there can never be a clear line of demareation between sound and diseased. Different observers can not hope to agree upon the number of the nodules which warrant a diagnosis of infection-whether there need be present 1,000 or 10 nodules. Neither call there be agreement 
as to what constitutes muco-purulent raginal discharge, if the amount is to decide the question. Unlike other females among our domestic animals, there is a well-nigh universal vulvar discharge of mucus or muco-pus from eattle, which raries quite as widely as the number of nodules present. There is a somewhat close harmony between the number of nodules present and the amount of vaginal discharge.

If it is held that the presence of nodules in the rulvar mucosa, be they few or many and accompanied by little or much irritation or discharge, indicates the granular renereal disease, the prognosis as to complete cure of the disease is hopeless in the present state of our knowledge. It attacks the heifer and calf ordinarily when a few weeks old, and, except at times near to parturition or abortion or under the influence of serious disease of the uterus (pyometra, etc.), the disease is still clinically recognizable in most aged cows. No more typically chronic malady is known, so that the terms acute, subcute, and chronic are mere expressions of the racillations in intensity dependent upon a great variety of causes.

From another standpoint we may regard the prognosis with some faror. Tiewing it as the possible cause of abortion and sterility, we know that during its zenith, when the animal is from 2 to 5 years of age, the economic losses from these causes aro greatest, and that after this period has passed the intensity of the disease abates, and with it the losses from abortion and sterility decline. So also we may regard as favorable the fact that we may repress the disease in its intensity and at the same time may decrease the losses from abortion and sterility.

Ostertag relates that one 6-year-old cow recovered spontaneously in $S$ weeks, but he does not define what he means by recovery. Thoms holds that after recovery from the disease the follicles slowly decrease in size, lout only in small degree, and then remain, and emphasizes his opinion that the cure of the disease is not necessarily followed by a disappcarance of the nodules. Hess (in a personal communication) holds that when the redness and swelling of the vagina and the muco-purulent dischare therefrom have abated the disease is curer; that is, it is no longer present, sterility fails, abortion does not occur.

When neerotic or other tissues become encapsuled, when inorganic salts are deposited in the tissues, when dense selerotic tissues have formed as a result of disease, and in many other cases, it is readily understood that the effects of the disease may persist indefinitely after the cessation of the malady. In the granular venereal disease investigators agree that the nodules consist essentially of masses of what appear to be round or lymph cells, cells of a very primitive 
character, with rarely a trace of skeletal stroma or of blood vessels anong them. Such structures, it would seem, would be rapidly and completely dissipated by physiologically active tissues as soon as the irritant which has caused them had abated. This view is fully borne out clinieally. Under varying conditions the numbers of nodules decrease rapidly. If the ragina is merely kept well douched with warm water and a mild antiseptic, a large percentage of the nodules disappear. If the nodules constitute the basic clinical phenomenon of the malady, it is difficult, considering their structure, to understand why, if the disease disappears, the basic symptom of it should not promptly follow

It is upon the partial disappearance of the nodules, muco-purulent vulvar discharge, etc., that the allegations of cure appear generally to be based. In other cases, howerer, the allegation of cure rests upon the swelling and edema caused in the rulvar mucosa by the application of an alleged remedy, by which the nodules are hidden. It is analogous to certain cures for exostoses on the legs of horses, wherein the neighboring soft tissues become so swollen and edematous from the application of the remedy that the exostosis is no longer apparent.

Referring to Table 1, in the group of cows 4 years old and over it may be assumed with safety that these animals had had an opportunity to recover spontaneously during a period of probably six years on an arerage, with the result that 85 per cent still showed the eridences of the disease. If we turn to Table 2 , it will be found that, of the 13 per eent marked negative, nearly to per cent may have been masked by adranced pregnancy, recent parturition, or pyometra. Considering that other diseases and conditions at times cause the symptoms to be temporarily masked, it is apparent that this group, of animals had mado no marked arlvancement toward spontaneous recovery.

Although continental European reterinary periodicals are well filled with contributions by leading reterinarians recounting the cure of the disease by rarious remedies, in many cases in the phenomenal time of 10 to 20 days, we have faithfully applied many of these over prolonged periods and have as yet not observed a single cure, evidently, again, because of a rariation in the definition of a cure.

\section{SIGNIFICANCE OF THE GRANULAR VENEREAL DISEASE.}

The importance of the granular renereal disease has been rariously estimated by different investigators. As shown by Table 1, the disease is so universal that its presence may be made to afford an explanation for a great rariety of ailments. When there is added to this the fact stated above of the wide divergence of opinion as to the clinical diagnosis of the disease, it naturally follows that different 
investigators assert, while others deny, that it causes any, few, or many losses, due to an extensive list of complications.

Some there are who rehemently assert that no such disease exists and hence can not eause losses. They believe the gramules or nodules to he normal structures, else, they say, they would not be so universal. Such granules or nodules, however, are not ordinarily observed in the vulvar mucosa of other animal species. They do not appear in the vulve of new-born heifer calves, and may not appear for months if the calf is kept in isolation. After coition they multiply by leaps and bounds.

Some urge that the disease can be of no material importance because it is so common and so few animals appear to suffer unfarorable consequences. The same argument has been applied to tuberculosis of cattle and glanders of horses. Te have come now to know that a very large percentage of each of these diseases goes unseen by the clinician and are detected only by biologic search. Te havo yet better analogies upon which tentative conclusions may be based. Te hare pointed out the fact that the disease is largely venereal in character. Though quite generally transmitted by other means, as is to some extent the case with all renereal affections, yet its intense arousal is brought about chiefly if not solely by coition.

In man and in each species of domestic animal there is one or more renercal disease, and each and erery one is of material consequence. In woman, syphilis and gonorrhea are responsible for much abortion, sterility, and chronic diseases of the ovaries, oviducts, and other organs. In dourine in mares, aside from the high mortality, abortion or sterility is practically constant and no viable foals are born. There appears no good reason for assuming that the granular venereal disease of cows should form any marked exeeption to the general rule that a chronic venereal infection of the genital tract is a serious peril, especially from the standpoint of reproduction in the affected animals.

\section{ABORTION.}

Among the various complications alleged to acempany the granular venereal disease, stoutly asserted by some and as vigorously denied by others, is ahortion. Here two riews as yet unreconciled clash-that of Bang and his supporters that abortion is due to the ahortion bacillus on the one hand, and that of Zschokke, Hess, and others that it is largely due to the granular venereal disease. At the outset it is well to bear in mind that the granular venereal disease and abortion are essentially universal. We hear now and then of the socalled breaking out of the granular venereal disease or of abortion in a herd, by which is ordinarily meant, not that the breaking out is the beginning of either malady, but simply that it has become so 
severe that it has attracted the attention of owners or veterinarians. If abortion is not playing havoc in a herd, the granular renereal disease may not be seen. No effort is made to see it. As soon as a large proportion of the cows begin to alort and an explanation is desired, search may be made for the granular renereal disease, and at once it is declared to have broken out, but all the time it was there. So with abortion itself. In small herds an actually risible abortion may not occur for years, or occur so rarely that the owner forgets the fact and he is ready to state that his herd has long been abortion-free. In large herds, however, of 50 to $100 \mathrm{cows}$ and over abortion is recognized as being essentially universal. Of course its contagiousness is often denied and a plausible explanation for the accident is given. The heifer (nearly always a heifer) has drunk too much coll water, has slipped and fallen, has been gored or kicked, crowded in a door, or suffered from some error in feeding, or from other causes too numerous to mention and to which all cows are inevitably suljected.

Contagious abortion is too often confounded with the death and expulsion of the immature fetus. It is not at all essential that a pregnant cow affected with contagious abortion must abort or that a fetus affected with the malady shall die. It is no proof that the infection or disease of contagious abortion is absent from a herd when no dead fetuses are expelled, and it is far from proof that the contagion is absent when but one or two animals in a dairy of 25 to 40 cows abort in a given year. We would better define contagious abortion of cattle as a chronic infection of the genital tract which may imperil the health or life of the fotus. The affection has been all too scantily investigated to permit of a conclusion as to what percentage of pregnant cows having in their genital tracts the organism of contagious ahortion actually abort. It is with certainty lnown that many of them do not abort. It is not at all rare to see cows giving birth to living, apparently healthy calves at full term, though at the commencement of labor they expel large rolumes of typical abortion exudate. A yet more familiar example is premature births, essentially all of which may be referred to the infection of contagious abortion. The infection may reside in any part of the genital tract, so far as now known, but can affect the fetus unfavorably only when within the uterine cavity. Even within this cavity it does not necessarily destroy the life of the fetus or even cause premature birth, but the birth may be apparently normal and the calf well developed and vigorous.

Our entire view of the differentiation between accidental and contagious abortion needs revision. The belief in frequent accidental abortion in the cow is so deep-rooted in the minds of veterinarians and cattle breeders that the question is one difficult of approach. $43378^{\circ}-14-3$ 
If we study the gravid uterus of the cow (or other ruminant) critically, the prorisions against accidental injury to the fetus impresses the observer as one of the most perfect physiologic arrangements to be found in animal life. The fetus of the ruminant is elaborately protected during intrauterine life. The pregnant uterus lies on a gently inclined plane, the abdominal floor, partly suspended by the ragina and broad ligaments. The fetus gets its nutrient supply, not ordinarily from a diffuse placenta as in the mare, or zonular placenta as in carnirora, where violence may cause placental detachment and entail fetal death, but instead procures its food supply through 100 or more cotyledons, complex multiple placentæ, each usually having a distinct neck, thus leaving an empty space between the uterus and chorion, permitting a to-and-fro movement between the uterine walls and fetal sac in every direction. The fetal security is further insured by its floating free within one and partly within a second sac of fluid.

As indicated by Table 2, the uteri of over 1,700 pregnant cows and heifers were inspected. Probably very few of them had been shipped less than 100 miles by railroad, many of them hundreds of miles. They had been driven some distance to a railway station, huddled into shipping pens, forced into cars, crowded and jammed, and not rarely got down and were trampled. At every turn opportunity was offered for crowding and jamming. Finally they were goaded into the killing pens, felled with a hammer, and tumbled out on the floor. Certainly they had been subjected to the dangers of mechanical and fright abortion. Yet, in all these cases, no trace of injury to the fetus, fetal membranes, or uterus which might possibly have caused abortion had the animal been allowed to live were seen. While such evidenee does not prove the impossibility of accidental abortion in cows, it does indicate that it is not, after all, very readily induced.

In further search for lesions of accidental abortion in stock-yard cows, two animals were purchased which had aborted in the car or rards and another had expelled a live fetus prematurely. 'These were killed within a few hours after the oceurrence. In none of the three was there a trace of mechanical injury, but lesions were found which are described elsewhere, showing conclusively that the abortion was due, not to mechanical injury, fright, or other accidental causes, but to an infection within the uterine cavity, the evidences of which could not have accumulated in a day or a week.

All other post-mortem examinations upon recently aborted cows, so far as found recorded, have uniformly shown, beyond question, that infection, not accident, was the essential cause of the death and cxpulsion of the fetus. No case of alleged accidental abortion in 
cattle, so far as we can find, has ever been verified by post-mortem examination.

Generally it may be said that the evidenee in relation to the inportance of the nodular venereal disease is purcly elinieal and circumstantial, while that of the abortion bacillus is chicfly from the laboratory. If the Bacillus abortus is inoculated into a pregnant heifer in order to test its virulence, it is injected into one affected with the granular venereal disease. If the granular venereal disease is capable of inducing abortion, and abortion follows the inoculation with the abortion bacillus, there is no conclusive proof which of the two infections, if they be distinet, eaused the disaster. It has not been shown that the Bacillus abortus of Bang is or is not related to the granular venereal disease.

There are many defects in the evidence submitted in faror of each hypothesis. If we examine first the Bang theory, we note among other defective points in the evidence:

1. Experimental inoculations have been without adequate control. To adequate evidence has been submited to show that, taken an equal number of pregnant cows or heifers of like age and other conditions, and, instead of inoculating them with the Bacillus abortus, they are given in the same manner (intravenously, hypodermically, etc.) an equal amount of an innocuous substance, such as salt solution, a similar precentage of the animals would not abort.

2. The alleged period of incubation required to induce abortion varies inconsistently, according to species. By referring to Tablo 3 , it will be observed that in cows the average time required to induce experimental abortion in the 26 cases recorded was 131 days; in ewes it required 6 to 83 days to induce abortion or infection; in the guines pig abortion followed inoculation after an averago of 10 days. In other words, the evidenco submitted suggests that no matter how brief the normal duration of pregnancy, an infection which usually requires an average of 131 days, or a trifle less than one-half the span of pregnancy in the cow, its natural host, so hastens its energies as to induce abortion in less than half the span of pregnancy in other species, no matter how brief that span may be. Indeed, the records of experimental infectious abortion in the guinea pig indicate that, abortion follows in one-sixth the span of pregmancy after inoculation. We are accordingly offered the phenomenon of an infectious discase, the duration of the incubation of which varies widely according to animal species, though each species may be equally susereptible. 
TABLE 3.-Average periods of incubation of abortion.

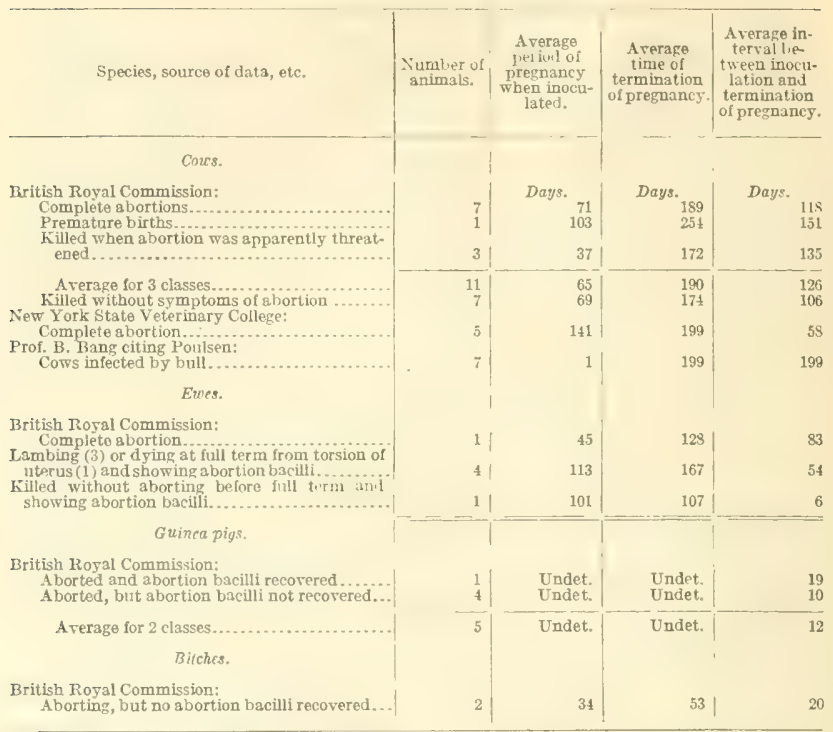

3. The data upen the duration of incubation in the cow vary in such a manner as to invite grave doubts as to the reasonableness of the conelusion that the artificially introduced abortion bacilus caused the abortion. Referring again to Table 3, wo find that the constancy of the average date of pregnancy at which the cows of various experimenters aborted is remarkablo 5 by Dr. Moore at the Now York State Teterinary College, averaging the one hundred and ninety-ninth dar: 11 by the British Royal Commission, areraging the one luundred and ninetieth day; 7 by Poulsen, citod by Bang, the one hundred and ninety-ninth day; and 3 by Bang the two hundred and fourth day.

In the columin recording the period of incubation the same lots show $126,5 S, 199$, and 114 days, respectively, which gives a very wide and inexplicable variation until a comparative study is made of the date of inoculation. It then appears that the period of pregnancy at which abortion occurred suggests that the duration of incubation is dependent upon the date of inoculation. In other words, inoculate pregnant cows at any date one likes, the average date of pregnancy at which abortion occur's remains tho same. We might say that, according to recorded data, tho inoculation at any time of a pregnant 
cow with abortion bacilli will tend to causo abortion about the two hundredth day of pregnaney, the organism tempering its rapidity of action according to the exigencies of the case.

If in Table 3 wo let $X$ equal the number of days elapsing after impregnation until inoculation is made and $Y$ equal the number of days elapsing between inoculation and abortion, then $I+Y=$ about 200 days, although the values of I and $I$ may each vary inversely from 1 to 200 .

4. The alleged cases of experimental abortion recorded by the different investigators present very grave questions in relation to the avenue or arenues of infection. These we discuss later in a separate chapter.

There is, it is true, much laboratory eridence tending to show that the introduction of the bacillus abortus intravenously, hypodermically, per raginam or orem, may lead to the invasion of the uterochorionic eavity and cause the death and expulsion of the fetus, but as jet no reliable means have been devised for determining that the same organisms did not exist already within the utero-chorionic space. Apparently a rery high perentage of the experimental heifers and cows inoculated have aborted, but this is merely comparative, not positive.

In the experiments of the British Royal Commission, of 5 heifers inoculated subcutem, 1 aborted; of 9 heifers inoculated intrajugularly, 4 aborted; of 5 heifers inoculated per orem, 1 aborted; of 9 heifers inoculated per raginam, 1 aborted; making a total of 28 heifers inoculated, of which 7 , or 25 per cent, aborted.

This rate of abortion does not greatly exceed the prerailing rate of abortions in first pregnancies. Iowerer, the commission determined, by autopsy or otherwise, that 11 additional heifers were infected and might have aborted, which makes a total of $1 \mathrm{~s}$, or $6 \pm$ per cent, of their experimental heifers that were infected. It is not at all rare for more than 64 per cent of heifers to abort from natural infection.

In each case we have found recorded of abortion, in cattle in which an early autopsy has been performed, there has been found in the utero-chorionic space a peculiar exudate which has not been recorded as occurring in other organs or in the uterus of other animals than the cow, and in which the abortion bacilli are usually, if not always, found.

As with the abortion bacillus, so with the granular reneral discase: there are no adequate control observations. Ender the conditions shown in Tables 1 and 2, no herds free from the granular venereal disease ean be found, and hence we can not say that, without that malady, contagious abortion could or could not exist.

It is a notable clinical fact, however, that those herds abort most in which the granular venereal disease is most intense. Then a large 
percentage of the cows and heifers have the disease of a severe typewhen the nodules are very numerous, the rulvar mucosa deeply injected, red, inflamed and bleeding upon slight provocation, when there is an abundant muco-purulent vulvar discharge, when the rulvar lips are swollen and the malady takes on what some term the acute type-abortion is usually common and serious. When the disease is mild, or as some say chronic, or others cured, learing behind, howerer, some clearly recognizable nodules, abortion occurs rarely.

A still more signifieant clinieal evidence that the granular venereal disease has an important relation to abortion is that abortion occurs at that age of the animal when the granular venereal disease is most intense; that is, in cows not over 4 years old. Usually it is during the first or second pregnancy that cattle abort when the granular venereal disease is at its zenith.

The granular renereal disease is also claimed to be the essential cause of sterility in cows. A great rariety of diseases may bring about sterility, as, for example, tuberculosis of the genital organs, but they constitute a rery small minority of cases. The rast majority of cases of sterility are due, according to our observations, to one widespread infection, inseparable from contagious abortion. In the experience of the writer, fully 98 per cent of the sterility of cattle must be regarded as identical in etiology with abortion. In one case the infection prevents conception; in another it attacks the embryo or fetus to cause its death and expulsion, or its expulsion from the uterus in an immature though living state (premature birth), or its birth in a more or less normal state, at full term, the infection existing in the uterus causing metritis with or without retained placenta.

Sterility and contagious abortion are in effect comparative terms, without any clear line of demarcation between the two phenomena.

THE GRAVID UTERUS OF THE COW.

The uterus is a branched, hollow organ, divided into a cervix, a body, and two horns.

The cerrix uteri is of great interest in the consideration of some of the phenomena of contagious abortion, as well as of sterility. In the nompregnant animal it is 3 to 6 inches long and 1 to 3 inches or more in diameter. Its walls are thick, dense, and resistant. The cervical canal is a narrow, tortuous channel, affording an avenue of communication between the raginal and utcrine carities. In the healthy nonpregnant cow, when not in estrum, the mucosa of the cervical canal is elaborately folded longitudinally. The folds are in immediate contact at every point, completely occupying the space of the channel, the eontact of the mueous folds being rendered close and firm by 
means of the powerful contraction of the thick muscular walls of the cervix.

Invasion of the uterine cavity through the cervical canal from the vagina is further guarded by a series of transverse muco-muscular projections directed sharply toward the vagina. These barriers are one-half to one inch in length and act as encircling valves directed toward the vagina in a manner to prevent ingress from the vagina by deflecting any invader from the cervical canal into the cul-de-sac of the valves, while pernitting a more free egress from the uterine cavity.

The anatomical arrangement of the walls of the cervical anal results in the channel being firmly closed in the normal nonpregnant cow which has not recently calved and is not in estrum. The closure is so firm, the canal so tortuous, and the valvular barriers are so effective that it is impracticable to insert a man's finger or even a sound from the vagina into the uterus. This leads to the popular delusion that sterility is caused by closure of the mouth of the womba wholly normal state. In our abattoir observations we incised the cervix uteri of over 1,500 nonpregnant cows and heifers and found in one only a closure of the cervical canal other than the normal approximation related above.

During estrum the cervical walls relux, the cervical canal dilates, and it is frequently possible to introduce a finger or sound into the uterine cavity. In severe cases of sterility accompanied by nymphomania the cervical canal is frequently dilated.

When pregnancy occurs preparations are promptly begun and early completed to hermetically seal the uterus. A tough transparent gelatinoid substance - the uterine seal forms in the cervical canul. It extends from the external to the internal os; pushes between the longitudinal mucous folds, pushing them apart while filling completely the spaces between them, fixing each fold in a definite position and binding it on either side to the adjacent folds; pushes the summits of the mucous ridges apart in the center of the canal, which it completely fills; invades and fills the spaces behind the transverse valvular folds; and binds and closes in a most intimate manner the entire cervical canal. The uterine seal projects beyond the internal os into the uterine cavity as a hemispherical elevation and posteriorly projects in a similar manner into the vagina, where it may be recognized by digital palpation as an elastic, adhesive mass adhering to the finger tip as it is withdrawn, constituting almost always a valid proof of pregnancy. It begins very early after impresnation, and is more prompt in heifers than in cows. It is generally complete in the heifer when the embryo is one-fourth of an inch long and in the cow when the embryo has reached a length of one-half to one inch, though 
it is rarely delayed to a somewhat later period. After completion in its formation, that is, after its complete investment of the parts, it continues to grow in volume throughout pregnancy, the rounded projections at the intermal os reaching in adult cows a diameter of 2 inches.

The uterine seal of the cow is a highly elaborate and interesting production apparently having as its office the simple function of a seal by which the uterine eavity with its contained young is hermetically sealed and invasion from the ragina excluded. In the more than 1,700 pregnant cows and heifers exanined on the killing floor the apparent efficiency of the uterine seal was well designed to excite admiration. The vagina might show marked evilences of longstanding infection, but the vaginal end of the uterine seal was firm, translucent, unstained, and to all appearances undisturbed by the infection. At its uterine end it was frequently stained by the hemorrhages generally present at this point and at times its surface partly liquefied. When the exudate of abortion was present at the internal os there was a more marked tendency to liquefaction of the uterine end of the seal, but in each case where the fetus was still intact and the membranes sound the body of the uterine seal revealed no changes whatever. It appeared as resistant to bacterial invasion as a living tissue; indeed it seemed more resistant than the neighboring mucosa.

When the fetus was dead and decomposing the uterine seal was dissolved and had partially or wholly disappeared.

The uterine seal is of especial significance in considering the avenue of infection and date of invasion in contagious abortion.

During estrum the uterine cavity contains a considerable quantity of rear mueus. At or near the close of estrum, succeeding closely upon urulation, in case impregnation fails to occur menstruation sets in. The mueosa then becomes injected, highly vascular, and swollen. The eotyledonal clevations of the mucosa enlarge, and from these a well-marked hemorrhage of bright-red blood oceurs which later escapes per rulvam (menstruation). Should impregnation ensue, menstruation ordinarily fails, and the uterus continues large, soft, and smooth. The fertilized egg soon throws out its embryonic sac or afterbirth, so that when the embryo reaches the size of one-eighth of an inch the embryonic sac is already quite large, as thick and long as an ordinary lead peneil, almost colorless, very thin and delieate, lying wholly free within the uterine cavity without any visible trace of placental attachment.

Later, when the embryo has reached a length of 2 to 3 inches, the placental attachments appear, at first very feeble, as faintly red patches on the chorion, gradually enlarging and thickening, the chorionic tufts becoming longer and more complex, white the coty- 
ledons of the uterus undergo corresponding development. The intimacy of contact between the chorionic and uterine placentre grow apace throughout the duration of pregnancy. Upon this fact is based the common observation that when abortion occurs before the fetus has reached or materially exceeded 12 inches in length it is ordinarily expelled inclosed within its membranes. This is of importance. While retained placenta or afterbirth is notoriously common and serious after abortion, it is not likely to occur in early abortion, but only in those cases which have reached or exceeded the sixth or seventh month of pregnaney. The tendency to retained placenta increnses with the advancement of pregnancy and reaches its highest degree in cases of premature birth, unless we except those cases which have reached the full period of pregnancy and given birth to living calves, in spite of extensive uterine infection.

It has been supposed and taught that the firmness of union between the chorion and uterus decreases toward the completion of pregnancy, and that the parts begin to prepare before parturition for the expulsion of the afterbirth. Observations on the killing floor directly contradict this assumption and show instead that the firmness of adhesion increases constantly up to birth.

Early in pregnancy the margins of the internal os uteri are thickly studded over with small placentre without marked peduncles. It times they form a complete girdle about the internal os, and come in contact with each other over the os to constitute a broad, flat placental mass 2 to 3 inches across, totally masking the os. However, they are not enduring, and when the fetus has reached a length of 10 to 12 inches they begin to become detached and finally disappear. In the process of detachment more or less placental hemorrhage ensues, so that in a large proportion of cases where the fetus is 10 to 15 inches long a careful observation of the utero-chorionic space at the internal os reveals a small blood clot, resting usually upon the uterine end of the uterine seal, where it undergoes retrogressive changes. At first bright red, it later becomes bluck, then fades slowly to a pale yellowish red, to constitute a sticky remnant staining the anterior end of the uterine seal. The amount raries; while usually but a drop or two, it may reach one-half ounce or more. As pregnancy advances adjacent cotyledons begin to detach about their peripheries and small hemorrhages occur. Whether physiological or pathological, the hemorrhage is suggestive of importance in relation to contagious abortion because at the rery point where the abortion exudate commences to form there exists generally an amount of inert blood coagulum to furnish a breeding ground for bacteria, like a blood clot in a wound.

Another phenomenon of a somewhat similar character is common among the larger, more typical cotyledons. As pregnancy advances $43378^{\circ}-14-4$ 
there appears at the periphery of many placenta a pale yellowishgray zone, very narrow, but showing a marked variation in color from the other parts. The pale zone upon examination consists of chorionic tufts which have been withdrawn from the cotyledonal crypts, and the tufts, losing their placental contact and function, become nonvascular and present a necrotic appearance. Their appearance suggests mechanical separation during the to-and-fro movements of the fetal sac within the uterine cavity.

\section{THE NECROTIC TIPS OF THE FETAL SAC.}

The cornual prolongations of the fetal sac grow out very quickly agrainst the apices of the cornua and are longer than the cavities they occupy, so that they become crowded and sinuous. At an early period the tip of the fetal sac in each cornu becomes necrotic and either extends forward toward the oviduct as a naked, flattened, yellow, hard cord, incrusted in a calcareous-like substance, or it becomes invaginated into the cavity of the ammion or allantois. In the gravid horn the necrotic tip is generally invaginated into the fetal sac, while in the nongravid horn it largely lies naked, 1 to 6 or more inches long, lying free in the apex of the horn.

When the necrotic tip is naked and exposed, when it comes in contact with the cornual mucosa, it is generally surrounded by a finely granular, yellowish or dirty lemon-colored fluid, suggesting a suspension of pale yellow brick dust in a fluid. There may be but a few drops, or the amount may reach 1,2 , or even 5 to 10 ounces. It appears like an exudate resulting from the mechanical irritation of the exposed necrotic tip and tends to be large or small in volume, according to the size of the necrotic tip.

While these necrotic tips are universal at the cornual apices, there appears rarely a very similar phenomenon at the internal os. Apparently in the few instances observed the fetal sae had pushed out for a distance through the internal os, and, like the projections into the apices of the horns, became necrotic, and was later surrounded by the pale, brick-dust sediment.

\section{PREVALENCE OF ABORTION.}

The history of contagious abortion of cows is extensive, though it loses much of its interest and definiteness because of the inadequacy of the means for its diagnosis.

Abortion statistics in any herd are necessarily inaccurate, and include only those cases in which the fetus has perished and been expelled at a period when its death and expulsion is recognized. In many outbreaks of abortion there is associated a large amount of sterility. Many of these instances of assumed sterility are in reality 
abortion. A cow will be served by the bull and fail to come in heat for two to five periods, convincing the owner that she is pregnant, when unexpectedly she again shows estrum. While such phenomena may depend upon a variety of causes, abortion unquestionably accounts for many of these cases. Occasionally the breeder chances upon the freshly expelled embryo, which may be only 3 to 4 inches long. Since these embryos come away inclosed within the fetal membranes, leaving no afterbirths, the discovery of the abortion is a remote possibility.

In rare cases the fetus dies from the infection of contagious abortion but is not expelled, and the cow or heifer appears sterilo. Two things may oceur: The fetus may undergo maceration, the tissues break down, some pus escape from the uterus, but largely remain in the organ as pyometra. In other cases the fetus does not break down, but desiccates to form an inert foreign body known as a mummy (lithopædion).

When pregnancy nears its close abortion again may escape unnoticed. A fetus may be expelled alive at the eighth month, or even earlier, because of the presence of the infection of contagious abortion in the uterus, and is commonly designated premature birth, though in fact its early expulsion is due to precisely the same cause as that which causes other fetuses to be expelled dead. Or, the infection being present, the fetus may live and develop up to the normal date for parturition, dio immediately preceding labor, and be expelled fully developed, fresh, but dead, and it is classed as a stillbirth, though just as evidently an abortion as is the five months' fetus, killed by the same infection. Abortion statistics in any herd can accordingly be merely approximate.

ABORTION DATA IN HERD A.

As a basis upon which to build an outline of the behavior of abortion in a herd, we submit statistics from herd $\mathrm{A}$ in Table 4 below. This herd at first consisted largely of grades, but was later changed into a pedigreed herd. The period covered is 22 years, which serves to afford a fair opportunity for arriving at the average rate of abortion. An average annual rate of 12 per cent of abortions is shown. The vacillations from year to year are exhibited in the diagram, figure 1, and the prevalence of abortion according to age in another diagram, figure 2. During the earlier part of the timo covered the herd consisted largely of adult cows, which were bought when mature, milked for a time, and sold. Later it has been the policy to grow all heifer calves and breed them. Thus there has been latterly a comparatively large number of heifers in first or second preguancy. 


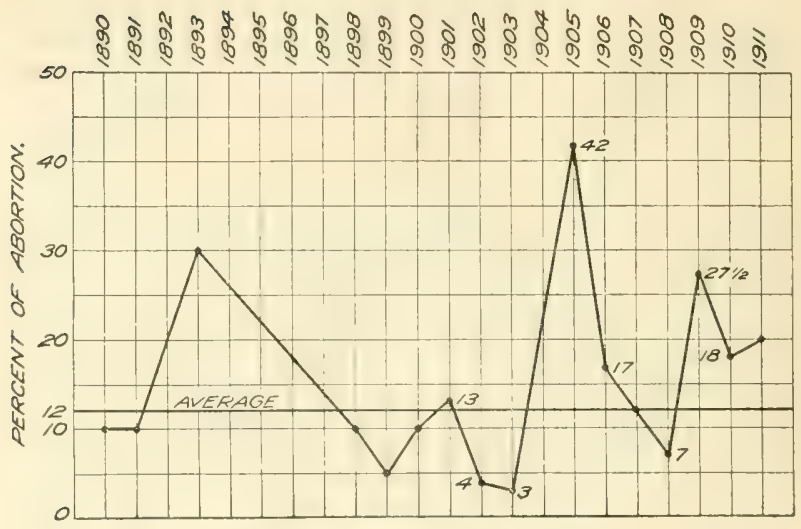

Fra. 1.-Percentage of abortlon in berd $A$, by jears.

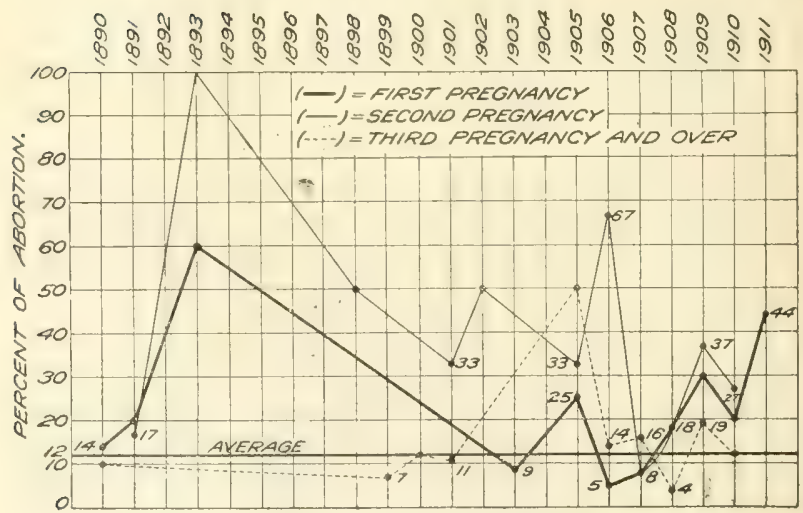

FIG. 2.-Intluence of the number of the pregnancy on the percentage of abortion in herd $A$. 


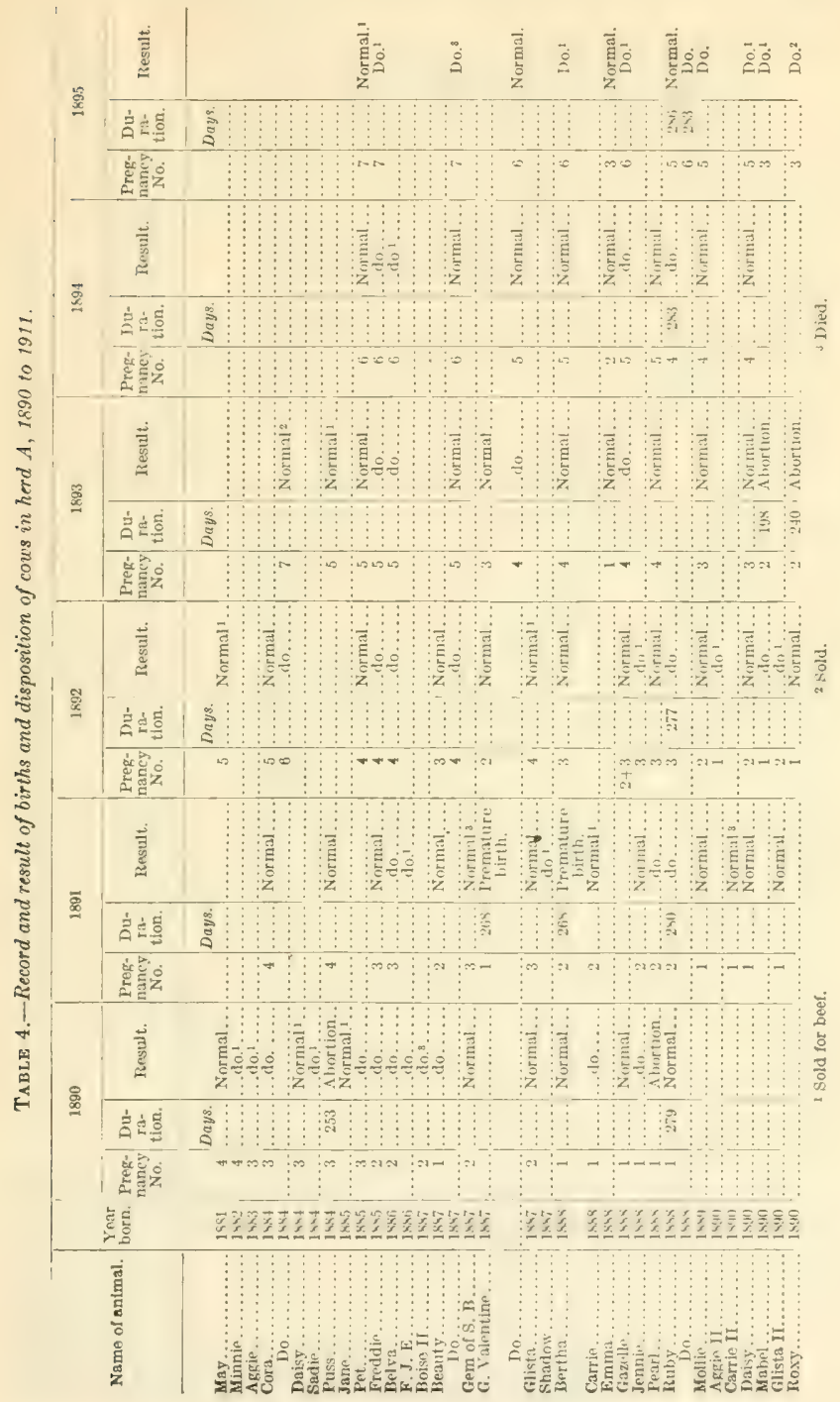




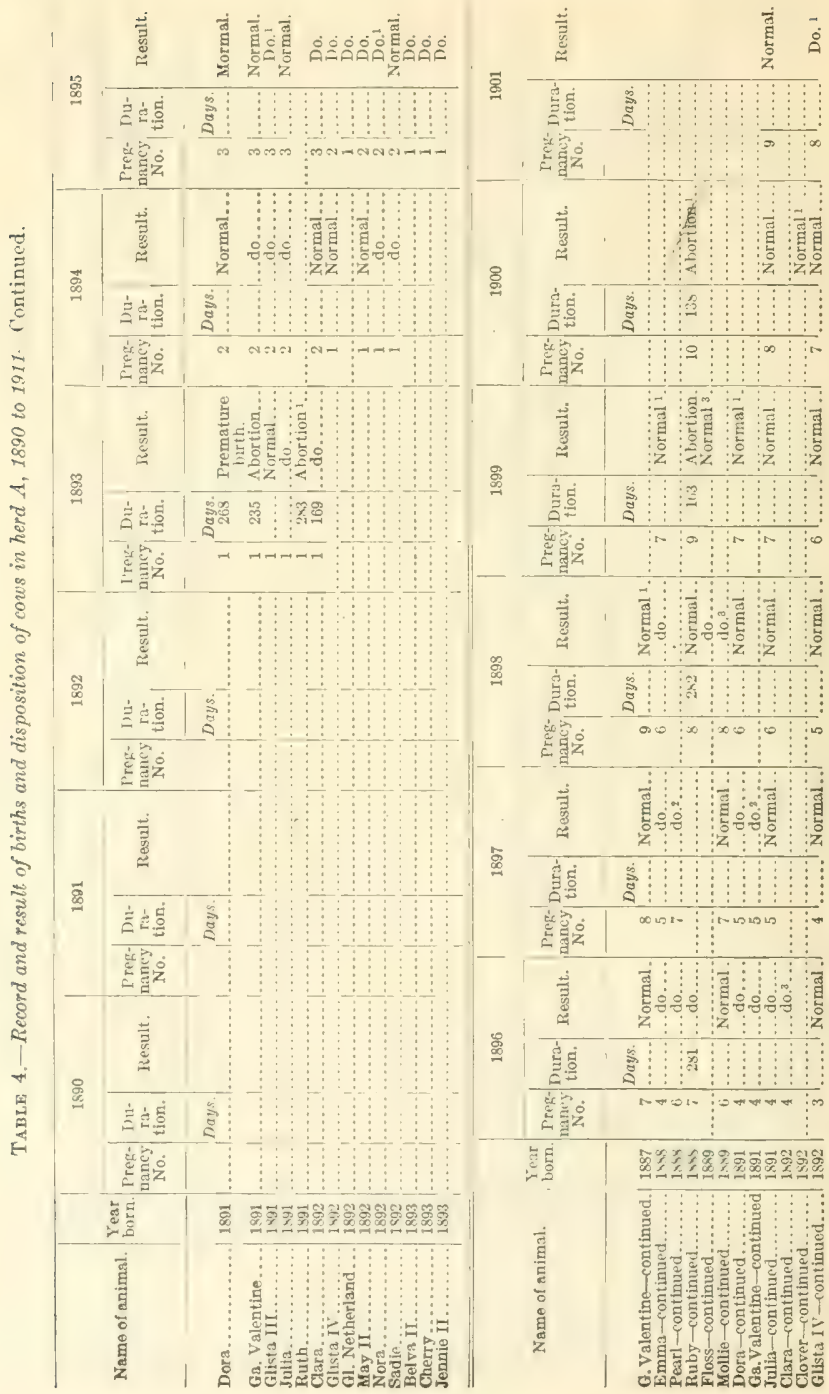


GRANULAR VENEREAl DISEASE AND ABORTION IN CATTLE. 31

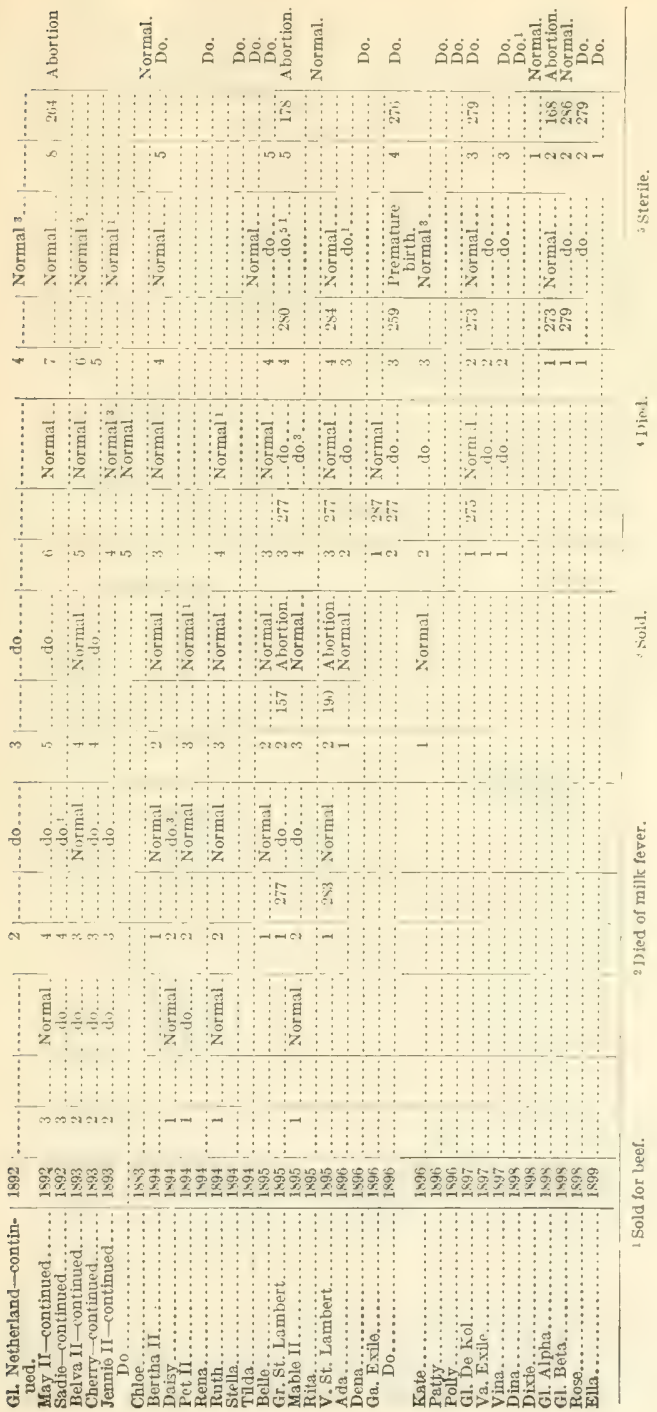




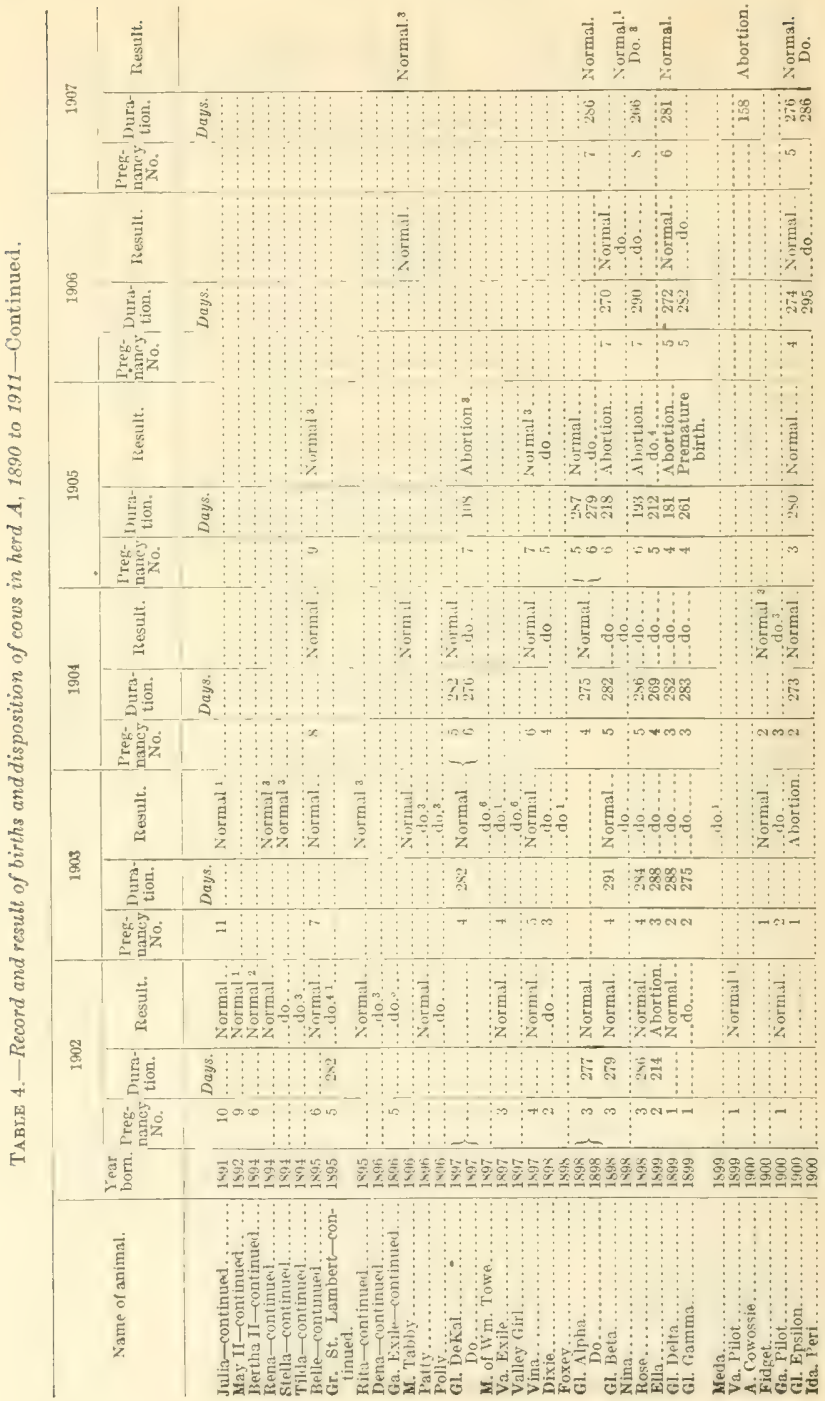


GRANULAR VENEREAL DISEASE AND ABORTION IN CATTLE. 33

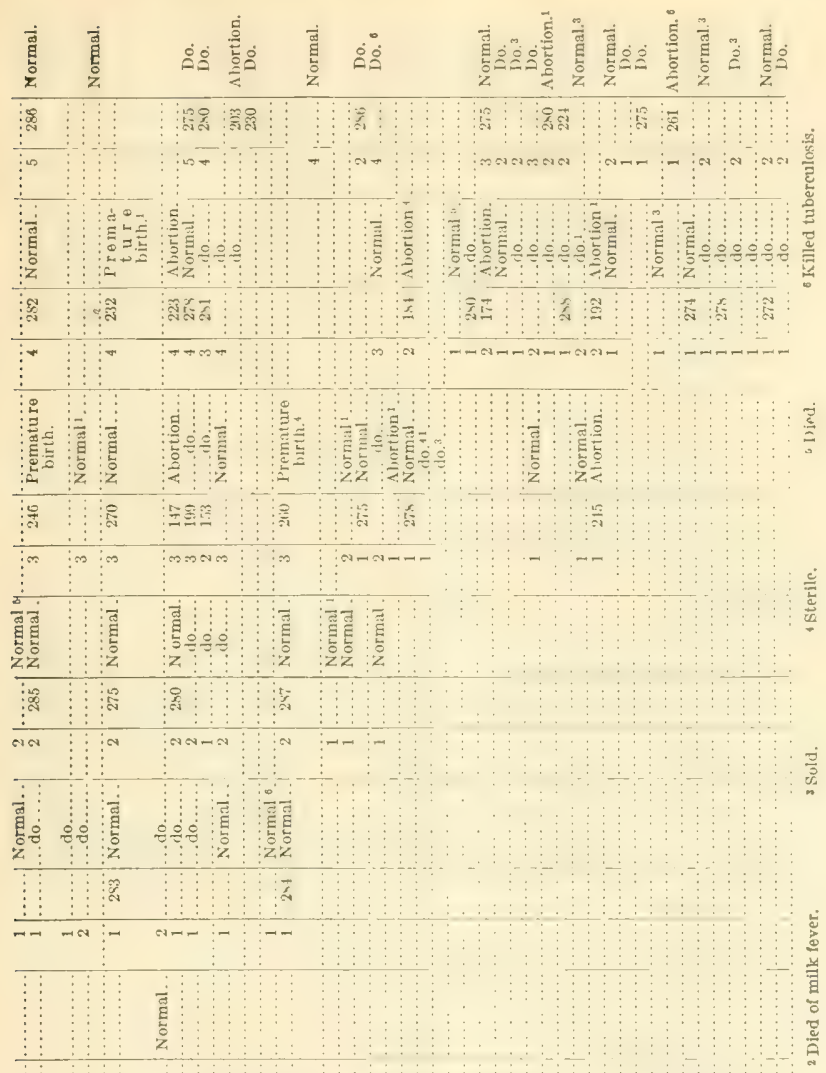

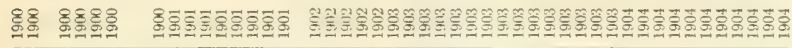

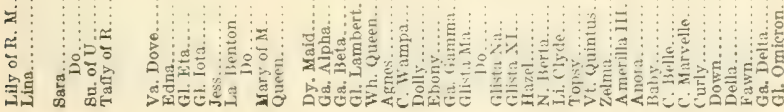


BULLETIN 106, U. S. DEPARTMENT OF AGRICULTURE.

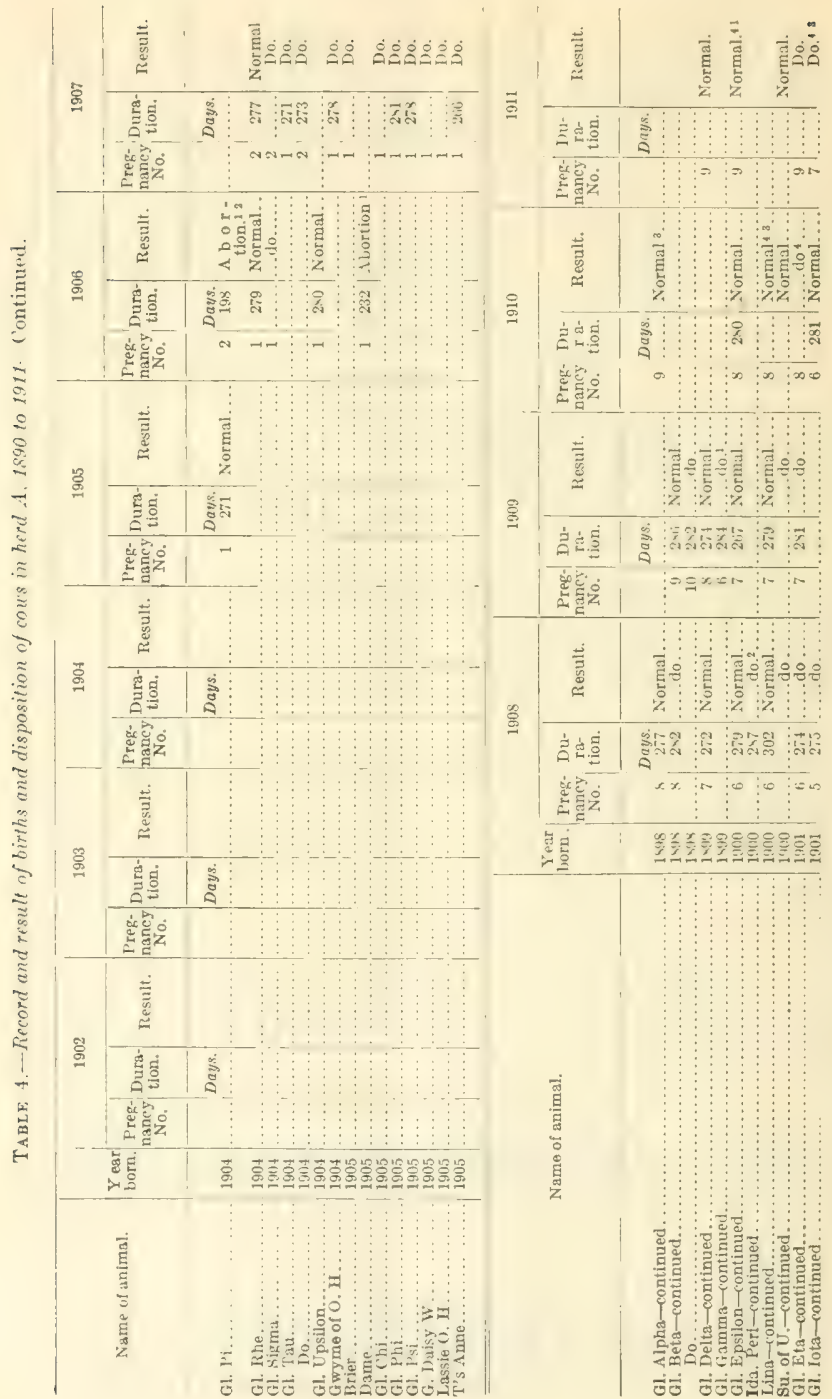




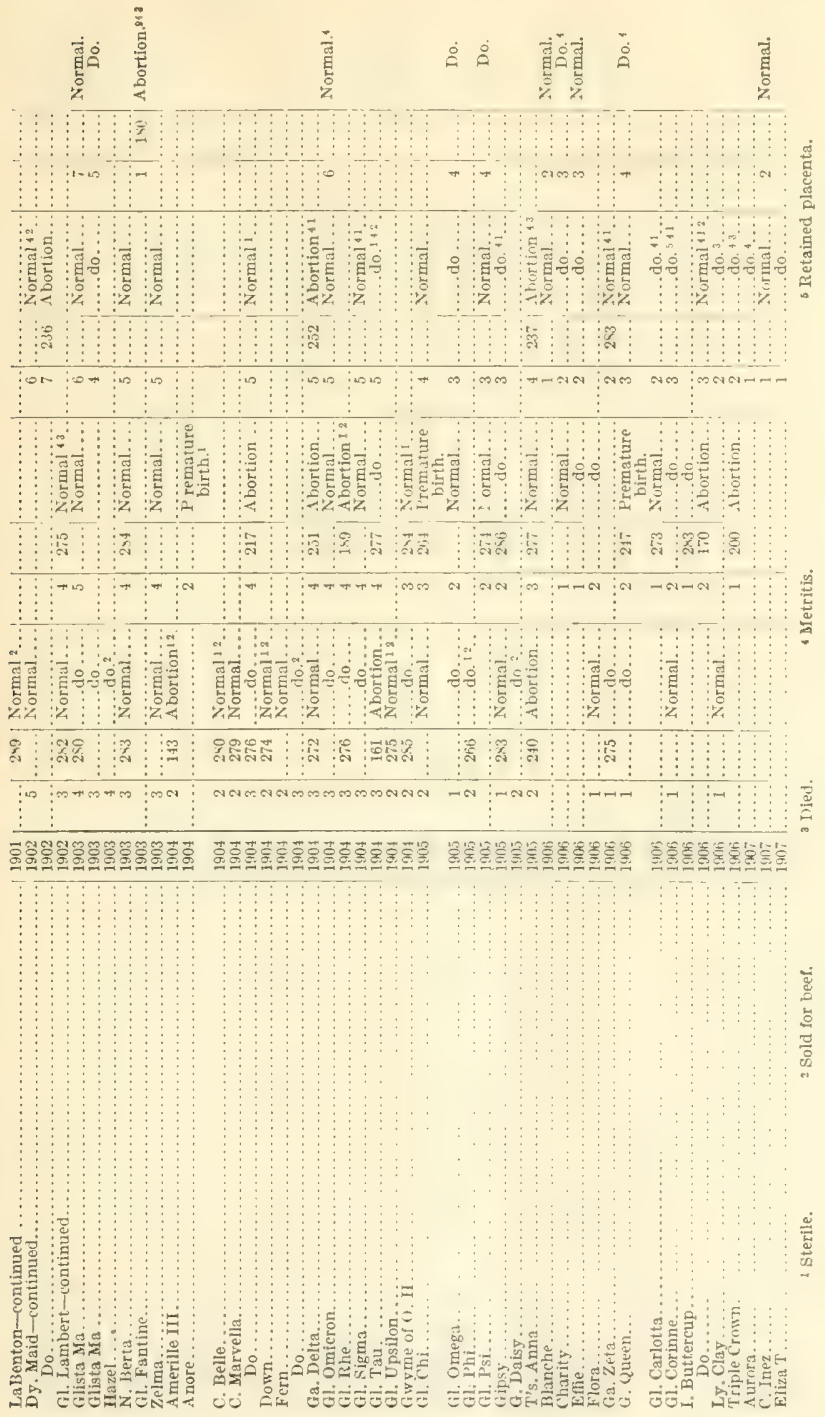


BULLETIN 106, U. S. DEPARTMENT OF AGRICULTURE.

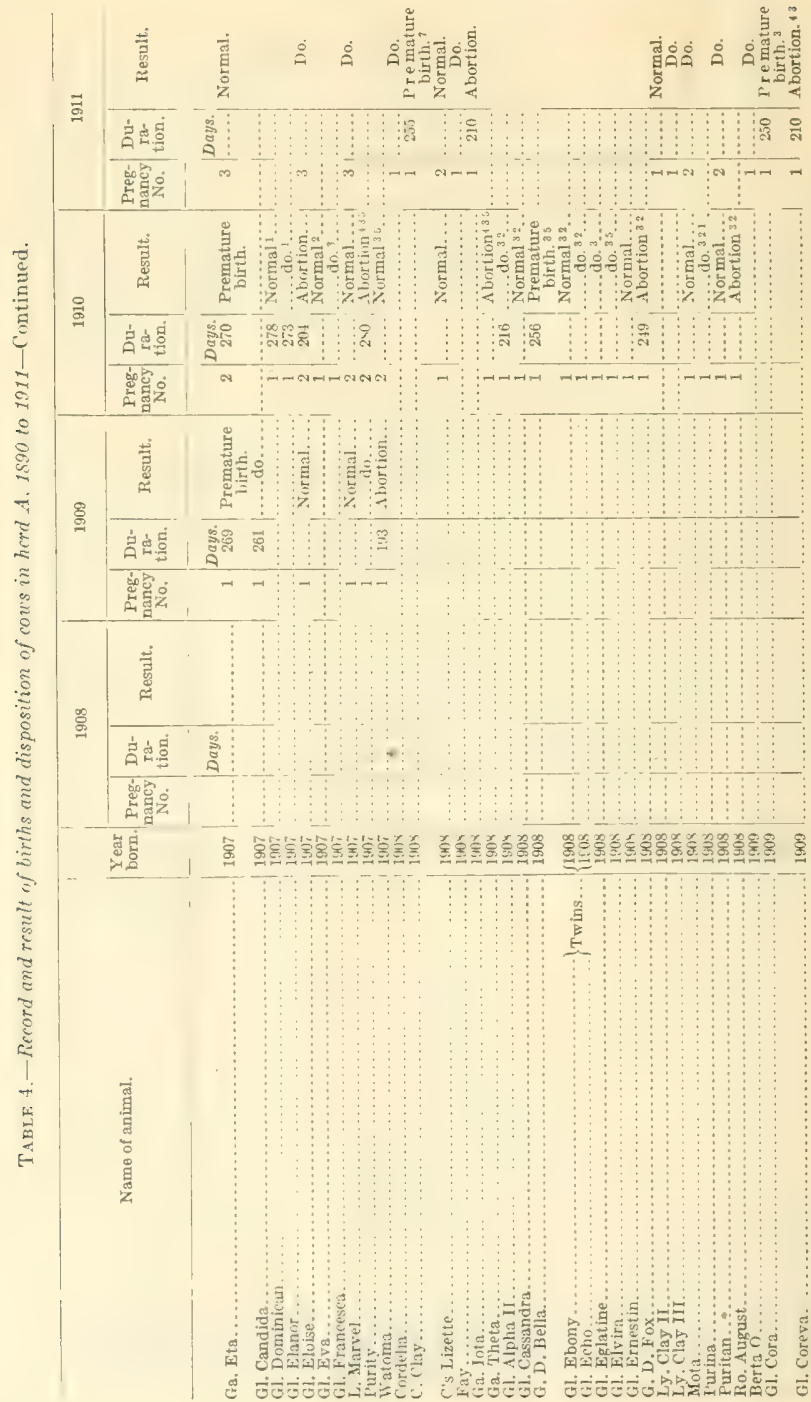


GRANULAR VENEREAL DISEASE AND ABORTION IN CATTLE. 37

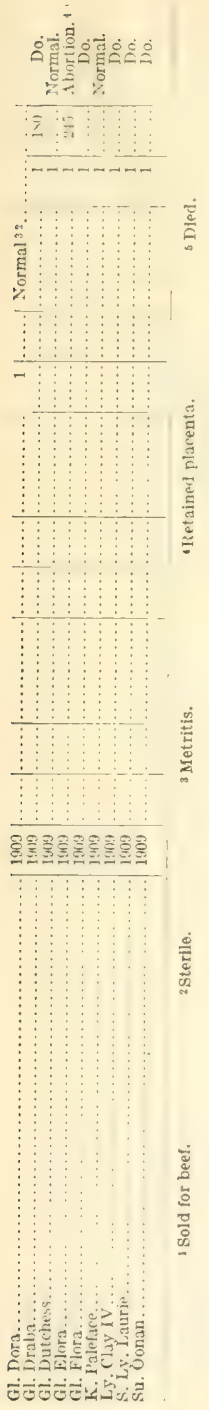


Figure 1 shows graphically the rise and fall of abortion above and below the average rate of 12 per cent in herd $\Lambda$ from year to year. The chart shows three abortion storms in which the percentage of known abortions exceeded 25, the most severe outbreak being in 1905, with recorded abortions in 42 per cent of pregnancies.

In figure 2 it is aimed to show the influence of age as expressed by the consecutive number of the pregnancy. The general aim in the herd has been to breed heifers at 16 to 18 months of age, so that the first calving ordinarily means about 2 years old, the second 3 years old, etc.

The intensity of abortion in first pregnancy seems to grow with the growth of the herd, while abortion in adult cows seems to decrease comparatively. As shown in figure 2, in 1911 the abortions in herd $A$ amounted to 44 per cent of first pregnancies, to which abortion was confined exclusively for the year. The first pregnancies were proportionally the highest in the history of the herd.

Summary of abortion data in herd $A$.

Total number of cows..................................... 217

Total number of pregnancies. . . . . . . . . . . . . . . . . . . . . . . . . 645

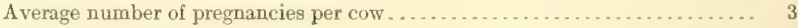

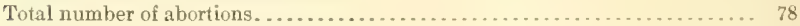

A verage abortions per annum................................. 3.5

Average per cent of abortions per annum...................... 12

Number of individual cows aborted. . . . . . . . . . . . . . . . . . . . 71

Percentage of cows which have aborted.......................... 33

Number of cows aborting twice............................... 7

Number of cows aborting twice in succession....................... 4

Number of cows died or killed after first abortion.................... 10

Number of years covered...................................... 22

Number of cows in which no abortion occurred...................... 6

Longest duration in years without abortion...................... 4

Highest number of consecutive pregnancies without abortion.............. 89

Among the 217 cows of herd $A$ occur the records of the first three or more pregnancies of 80 indiriduals. Of these 80 animals, 18 were in the herd in 1905,2 of which had aborted previously, and in one of these (50 per cent) abortion recurred.

Of the 80 cows in Table 4 of which we have records of the first three pregnancies, there were aborting in the first or second pregnancy 20 , or 25 per cent; in the third or later pregnancy 18 or 22.5 per cent; while the number not aborting was 42 , or 52.5 per cent.

The chronological order of abortions in these 80 individuals in their third or later pregnancies is shown in Table 5. The figures in parenthesis indicate that one animal in a group aborted a second time in the number of her pregnancy indicated by the figure. 
TABLE 5.-Chronological order of abortions in cows of herd A from third pregnancy onvard.

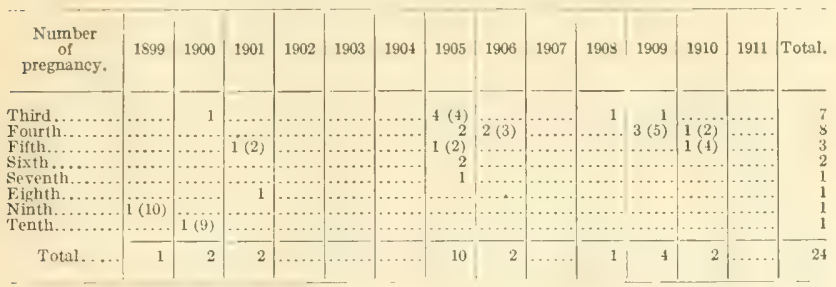

Table 5 shows that when cows abort in their third or later pregnancy it usually occurs in a storm like that of 1905 . Thus, in the 80 animals tabulated, 10 abortions, or 41 per cent of all the abortions in third or later pregnancies, covering a period of 22 years, occurred in one year. Fifteen of the 24 abortions occurred during the third and fourth pregnancies, thus indicating strikingly the influcnee of the age of the animal upon abortion.

ABORTION RECORI IN HERD B.

In the following data of herd $B$ the annual rate of abortion increases from the 12 per cent of herd $A$ to 17 per cent. The increase occurs not in adults, but in heifers, and especially in those pregnant for the first time.

Summary of abortions in herd B, May, 1909, to December, 1911.

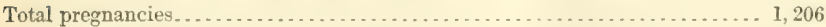

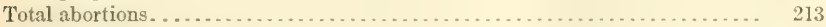

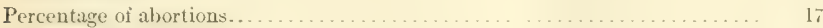

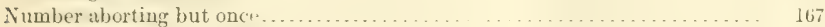

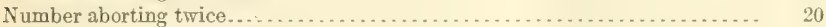

Number aborting thrice.................................

Total number of cows aborting............................. 189

$A$ bortions in first pregnancy, 99 , or 46.5 per cent of all abortions and 50 per cent of first preguancies.

Abortions in second pregniney, 70, or 33 per cent of all abortions and 34 per cent of second pregnancies.

Abortions in third pregnancy, 26, or 12 per cent of all abortions.

Abortions in fourth or later pregnancy, 18, or 8.5 per cent of all abortions.

\section{Repeated abortions}

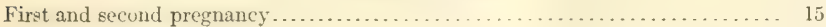

First, secund, and third pregnancy....................

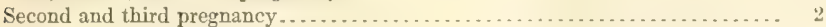

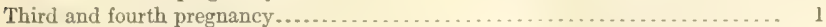

Fourth and fifth pregnancy.................................. 1

Fifth and sixth pregnancy................................

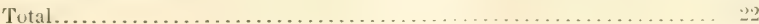


Other abortion statistics available to us would not modify essentially the general picture of the disease. Generally we believe that the average rate of abortion in pedigreod herds falls between 10 and 15 per cent per annum, rising and falling from year to year, unseen possibly in the smaller herds for one, two, or three consecutive years, then showing itself again, gathering force for a while, and culminating in a great explosion of the disease which forces the percentage of loss up to 30,50 , or 75 per cent, or even higher. It is not at all rare in a group of 10 to 20 heifers pregnant for the first time for the abortion loss to reach 90 or even 100 per cent. In small herds of 5 to 15 or 20 animals, mostly adults, the percentage of abortion is usually far below the above ratio.

\section{SYMPTOMS OF ABORTION.}

The symptoms of cattle abortion are as yet extremely vague. They popularly fall into three groups the signs of impending abortion, the phenomenon of aborting, and the eridences that abortion has occurred.

The symptons of impending abortion comprise chiefly tumefaction of the udder and of the vulva, vaginal discharge, and sinking of the broad ligaments of the pelvis, any or all of which may fail or may be deceptive. Tumefaction of the udder is not common unless the pregnancy has passed the fifth month; even then it is not reliable. In milking cows it is usually unobservable. The erroneous assumption that tumefaction of the udler indicates that a heifer will certainly abort leads to the error that the use of certain nostrums have blocked an impending abortion. Heifers pregnant for the first time not rarely suffer from a severe mammitis or garget as early as the sixth month, which has no known relation to abortion. Heifers which have never been in calf show at times swelling of the udder, and may even milk frecly. The sinking of the pelvie liganents is more indicative of impending abortion, and may be regarded as an unfarorable sign when present, but this is only in a minority of cases.

The evidences of the act of the expulsion of the fotus are largely dependent upon the duration of pregnancy, becauso the force required for its expulsion naturally depends upon its dimensions. In the earlier stages of pregnancy no expulsive efforts are seen, and it is only by the chance observation of the embryonic sac passing through the vulva that the act is observed at all. As pregnancy becomes more adranced the expulsive act assumes more and more the general aspect of normal parturition.

If the act of the expulsion of the fetus passes unobserved and the afterbirth has come away, there is littlo to indicate that abortion has occurred until the cow again comes in heat. If she is well advanced in pregnancy the abortion is very liable to bo followed by retained placenta, which is usually clearly recognizable. 
The definite elinieal diagnosis of impending abortion is esisentially impossible until the condition has so far adranced that the preliminary acts of abortion, as dilation of the cerrical canal, protrusion of fetal membranes, ete, hare become established. The determination of the fact that abortion has oceurred must be based upon the recognition of the expelled fetus or afterbirth as belonging to the animal, or, if it is known that she has been pregnant, it must be established by rectal or other examination that pregnancy has terminated.

The differential diagnosis between aceidental and contagious abortion is largely impracticable in the liring animal. It has been proposed to differentiate them in a variety of ways; for example, to separate the two classes of abortion by recognizing the presence of the Bacillus abortus in the placenta or uterine exudate of the one group while it is absent in the other. While some have laid claim to the possession of such skill, the accuracy of the conclusion that merely negative findings indicate the absence of contagious abortion does not seem wholly warranted.

MeFadyean and Stockman, Sren Mall, Holth, and others claim much for the diagnosis of the disease by means of the complementfixation and agglutination tests. Thus far, howerer, it has only been shown according to data subnitted that certain animals which had recently aborted reacted. They have not shown that all reacting animals are bearers of the infection of abortion, nor that all bearers of the infection react. The character of the conclusion from the data assembled is well expressed by Wall: "A reaction indicates that the animal is or has been infected with contagious abortion." Animals which had aborted quite commonly reacted more than two years after abortion. Apparently an impending abortion may not ordinarily be foretold by these tests.

The post-mortem diagnosis of contagious abortion appears to be more certain and the phenomena fairly well established, especially in relation to the presence of the abortion exudate. This exudate, in the present state of our knowledge, is characteristic and conclusive. However, post-mortem examinations upon cows which have recently aborted have been all too few in number, but the phenomena presented are very uniform. Te have had opportunity of making post-mortem examinations upon seren recently aborted cows and heifers, with the following results, which were in each case essentially identical:

Case 1.-A 2-year-old Hereford heifer shipped from Garden (ity, Fans, on May 17 to Kansas City and unloaded the following morning. It was found that during the night of May 19 she gave birth to a small, weak, live calf, at apparently about the eeventh month. She was slaughtered about $11 \mathrm{a} . \mathrm{m}$. The heifer was in good general condition and apparently healthy. 
The calf, a heifer, was very weak, unable to get up or stand. Its hair was long, shaggy, and lusterless. It had the general appearance of emaciation. It measured 31 inches from occiput to base of tail and weighed 25 pounds. The buttocks were soiled from thin yellow diarrheic feres. The calf was destroyed at $10.30 \mathrm{a}$. m. by bleeding from the carotids, and the body cavity was laid open along the median ventral line. The spleen was markedly hemorrhagic. The liver was swollen, tense, glistening, and showed hemorrhagic areas. It was distinctly icteric in appearance. The heart showed hemorrhages beneath the perirardium along the groove hetween the ventricles.

The examination of the genital organs of the ahorting heifer revaled the following changes:

The vagina was congested at the anterior portion and contained some dirty reddishgray mucus, streaked with blood and apparently containing some pus.

The uterus measured 22 by 38 inches. Its exterior offered nothing notably abnormal. The walls were a trifle thick, dense, and opaque. The organ seemed plump, and involution apparently progressing favorably. There were no evidences of mechanical injury.

The cervical canal was dilated and its mucosa was ecchymotic (parturient contusion).

The fetal membranes were all retained. Those of the nongravid horn were edematous. Aside from the rent at the internal os through which the fetus was expelled, the membranes were intact and exhibited no trace of merhanical injury. About the internal os a few cotyledons were detached from the chorion, and all the cotyledons were readily detachable. Aiter detachment the chorionic tufts were pale, dirty yellow, and adhesive to the finger, like the abortion exulate. There were small interplacental hemorrhages, but nothing beyond what is usually oberved in healthy gravid uteri. The inner surfaces of the amnion and allanteis appeared normal and their cavaties were empty. The uterine contents were odorless.

The uterine mucosa was pale yellowish, dense, thickened, and somewhat granular in appearance.

In the utero-chorionic space of nongravid horn there was an abundant, dirty gray, floceulent, viscid, puriform exudate, quite tenacious in plares, and especially abundant at the base of the horn and for 10 or 12 inches toward the apex, after which the cavity was empty.

In the gravid horn the exudate was very abundant and identical with that in the nongravid horn. It was most abundant near the internal os uteri and for a distance of 20 to 25 inches along the greater curvature. diminishing toward the apex of the horn until in that region the mucosa was approximately normal and clean.

Case 2.-A heifer apparently 2 years old and estimated at 625 pounds weight ahorted in the car during transit to Kansas ('ity. Nearly all the animals in the car were affected with nlcerative ano-vulvitis. The abortion was discovered about $9 \mathrm{a} . \mathrm{m}$. The vagina was extensively ulcerated, cankerous-appearing, red, and bleeding at touch. The broken end of the umbilic cord lay within the rulva, appearing comparatively fresh.

The animal was killed by bleeding at $3 \mathrm{p} . \mathrm{m}$., and the autopsy followed immediately. The uterus, vagina, and vulva were removed intact.

The uterus measured $16 \frac{1}{2}$ by 28 inches, was plump, firm, more opaque than a pregnant uterus, but except by careful examination would be passed as a gravid uterus with a fetus 4 to 8 inches long.

The uterine peritoneum was apparently normal and showed no visible traces of traumatism. Upon incising the uterus it was found that the fetal membranes were completely retained. A few cotyledons, in fact approximately all those in the cavity of the body of the uterus, were detached from the chorion. The chorion of the nongravid horn, except at its base, was also detarhed from the cotyledons. In the gravid 
horn the chorion was firmly adherent to the cotyledoms and attempts to detarh it resulted in its giving way and the chorionic tufts being more or less completely retained in the cotyledonal crypts.

The cotyledons were 2 to 3 inches in their greatest diameter and deeply injected, brownish-red in color. The intense injection extended one-lialf inch or more into the cortical substance of the cotyledons, after which they appearel a dirty, necroticlike, yellowish-gray color. The cotyledons were hard, swollen, and infiltrated.

The afterbirth was retained due to cotyledonitis, which bad evidently antedated the expulsion of the fetus and would probably have resulted eventually, had the heifer lived, in total necrosis and sloughing of the cotyledons. The placenta was not markedly putrid. There was but little if any fetor present. The odor was rather of an unpleasant sweetish character.

The chorionic tufts were soft, adhesive, and necrotic-looking. The tufts, where detarhed from the cotyledons, would stick to the fingers. The amniotic and allantoic cavities were empty except for scattering fragments of tissue débris or coagula.

The utero-chorionic cavity was filled with a puslike substance throughout its entire area. The exudate was dirty gray, floceulent, floating in thinner liquid. It wanted that adbesiveness usually observed in the abortion exudate in clised uteri. The admixture of fetal fluids had served to change the physical character of the exudate.

The uterine mucosa was inflamed, thickened, uneven, and granular in appearance. In some areas there was a dirty-gray firmly adherent exudate; in other areas the mucosa was naked, injected, inflamed, and showed petechial hemorrhages. The fetus was 28 inches from occiput to sacrum.

Case 3.-A 2-year-old heifer which had been driven a distance of 25 mile's and yarded overnight in the Denver stockyards on June 2, At $7.45 \mathrm{a} . \mathrm{m}$. June 3 she expelled an 11 -inch fetus with the fetal sac complete. The heifer was slaughtered 4 hours after she aborted.

The carcass was thin and emaciated. The mammary gland was enlarged as though parturition were impending. After slaughter there escaped from the vulva one-half ounce or more of a dirty-grayish, flocculent exudate, faintly tinged with red. After the removal of the skin no traumatism of the body walls could be detected. Granular vaginitis was well marked, but not intense. The uterine walls were one-fourth of an inch thick, vascular, and petechial.

The uterine cavity, including both horns, contained 3 or 4 ounces of a dirty-looking, flocculent exudate, floating in a thin watery liquid. The clumps of exudate rere somewhat viscid, and the masses were largely adherent about the pedicels of the cotyledons.

The exudate had the general appearanee of that described as the typical exudate of contagious abortion, but its glutinous character had been modified by the presence in the cavity of portions of the amniotic and allantoic fluids.

The cotyledons were $1 \frac{1}{2}$ inches in diameter, hemorrhagle in the cortical area, and the surface was scarlet in color, like oxygenated blood. The cotyledonal crypts contained some chorionic tufts.

The chorion was edematous, one-half inch thick, and comparatively free from odor. The chorionic placental areas were pale, soft, and sticky.

Case 4.-Inoculated May 2, 1911 (10 c c of abortion-bacillus culture in the jugular vein), aborted May 9 and killed May 10, 1911. A few cotyledons near the internal os were scarlet. The cotyledons were covered more or less irregularly with a yellowishgray substance resembling pus in consistency, but more yellow. This was found over the majority of the cotyledons. There was very marked edema beneath the mucosa near the internal us, and in this region were also several areas of redness

Case 5.-Inoculated May 2, 1911 (15 c. c. of ahortion-bacillus culture in the jugular vein), aborted May 28 and killed May 29, 1911. The placenta showed considerable 
edema. In the uteru-chorionic space there was an abundance of a sticky yellowish substance in small masses 1 to $5 \mathrm{~mm}$. in diameter. Some of the cotyledons were scarlet. The organism of abortion was recovered from the uterus.

Case 6.-Inoculated May 2, 1911 ( 15 c. c. of abortion bacillus culture in the jugular vein), aborted July 25, and killed July 26, 1911. In the utero-chorionic space there were found numerous irregular masses of a yellowish substance that tended to adhere to the chorion. This substance was in small llakelike masses varying in size from 1 to $10 \mathrm{~mm}$. in diameter and from 1 to $3 \mathrm{~mm}$. in thickness. It was also found around the separated cotyledons and was very much in evidence in the fundus of the uterus, where it harl been washed by the fluids. A few cotyledons near the internal os were scarlet. The chorion showed sight edema throughout. The organism of aburtion was recovered from the uterus.

Case 7 .- Inoculated May 2, 1911 (10 c. c. of abortion bacillus culture in the jugular vein), aborted July 26, and killed July 26, 1911. The gravid horn of the placenta showed marked edema. A substance similar to that found in the utero-chorionic space of Case 6 was found, but was present here in a much smaller amount. The organism of abortion was not recovered.

The lesions recorded in the foregoing appear identical with those described as typical of contagious abortion. The uniformity with which the abortion exudate has been demonstrated in all recorded autopsies immediately following abortion in cows witnesses strongly that the abortion exudate has an essential relation in the eausation of contagious abortion, and, so far as the small number of recorded autopsies can support, indicates that abortion in cows is an essentially contagious disease and that mechanical abortion is rare and negligible.

PHENOMENA WITHIN THE UTERINE CAVITY.

During our investigations we observed numerous instances where some suggestive phenomena appeared within the uterine carity. Twenty-two of these cases presented eridences warranting the conclusion that the infection of contagious abortion was present, or (in cases where the fetus had perished and undergone more or less disintegration) that they had been infected with contagious abortion. While the cases vary somewhat in their character, they agree in a general way with each other and are in substantial accord with the lesions observed in the uteri of cows killed immediately after abortion.

Case 1.-Age four years, length of fetus 31 inches, right ovary normal, left ovary corpus luteum. Lterine seal intact. Exterior of uterus normal. The utero-chorionic space was filled throughout with an exudate of a dirty grayish color, puslike in appearance, odorless. The exudate was thickest at the cervix. The total amount of exudate was estimated at 1 gallon. The uterine walls were not materially thickened, the uterine mucosa was injected with some small, necrotic-appearing patches. The cotyledons were freely detachable, but not materially altered. The chorion appeared normal in thickness in the gravid horn, edematoms in the nongravid. The uterine surface of the chorion was injected.

The allantois, amnion, and fetus were apparently normal.

Case 2.-Aged cux, fetus full term. Tterine seal intact. Utpon opening the uterine cavity a yellowish-brown, thugh exudate was found about the os uteri internum. 
Case 3.-Aged, length of fetus 36 inches, about full term. Uterine seal softened. Vturi-churinic space contained a touch. jalle yellowi-h-red puslike mass of exulate about the internal os. Further from the os internum, the utero-chorionic space containe 1 much uterine sand, bright orange-cul red. While the exudate extended over the entire uterw-rhorionic space, only that racliating from the internal os was typical of contagious abortion.

Case 4-. Aged, embryo $2 \frac{1}{2}$ inches. Tterine seal ab-ent, either unformed or broken duwn. Ttero-chorionic space contains 10 to 12 ounces of thin, grayish-yellow purulentlike exudate. Fetus apparently normal.

Case 5.-Two-year-old, fetus 18 inches. Uterine seal softened and partly broken down at internal os, but intact and normal elsewhere. Radiating from os uteri internum in the utero-chorionic cavity for a distance of 4 inches is a tough, dirty grayishyellow exudate.

Case 6.-Aged cow. Length of fetus 16 inches. Uterine seal intact. Abortion exudate in uteru-chorionic space radiating from internal ws uteri 2 to 3 inches in the nongravil and 12: to 15 inches in the gravid hurn, mostly in flat, reddish-brown, tough, gluey masses 1 inch long by one-eighth inch thick. In other places the exudate is a dirty grayish yelluw colur, either semifluid or in tough, flat masses. The exudate is depusited chiefly about the cotyledonal stalks, especially the more primitive ones about the internal os.

Case 7.-Aged. Length of fetus, estimated 6 to 9 inches. Uterine seal destroyed.

Iforns 3 inches in diameter by 10 inches long, hard, tense, with sclerotic walls onehalf inch. Uterine cavity contained 4 ounces of thin, brown, flocculent pus in which were masses of bones apparently from a fetus 6 to 9 inches long. Apex of right horn adherent to broad ligament. Abscess in uterine end of leit oriduct containing one-eighth ounce thick yellow pus.

Case 8.-Aged. Twin pregnancy. Fetuses 9 inches, apparently long dead, macerated, dirty gray, soft, odorless.

Amniotic and allantoic fluids dirty gray, flocculent, nparue, odorless, chorion completely detached. Fetal membranes edematous, one-half inch thick. Uterochorionic cavity filled with fluid like that in amnion and allantois.

Case 9.-Aged. Length of fetus, 30 inches. Uterine seal orange-colored and broken down. (trange-yelluw, gluey masses of exudate about the internal as 1 by ove-eighth inch in size.

Case 10.-Four-year old. Length of fetus, 2 inches.

The -horion of the left (nongraviil) horn was detached from the right portion, necrotic, dirty grayish in color, and surrounded by a dirty-grayish fluid exudate. A tough yellowish exudate in the utero-chorionic space at internal os.

Case 11.-Aged. Fetus full term, apparently alive at time of slaughter. Exterior of uterus normal. Uterine seal apparently somewhat softened; otherwise normal.

Ltero-chorionic space filled with exudate throughout, exrept at one point ingreater curvature of the gravid horn, which appeared normal. The exulate varied in appearance, dirty redklish-gray in color, in some places collected in irreurular, flat, firm, gluey masses 2 to 4 inches by one-eighth inch and at other points a semifluid, viscid mass.

The exudate was thickest about the internal os uteri, and from that point radiated out 18 inches to the apex of the nongravid horn, and 48 inches or mure to the apex of the gravid horn. The gluey masses were largely adherent about the cotyledonal stalks. The chorion was markedly edematous, 1 to 2 inches thick.

Case 12.-Aged. Full-term fetus. Uterine seal intact. Utero-chorionic space filled with an abundant, tough, orange-brown. very gluey, sticky exudate, radiating wit irom the intermal os $t$ inches in the nongravid horn and 12 in hes into the gravid horn, larem massed alout cotyledonal stalks, lut in places extrudiner from cotyledon to cotylerton. Exulate une-fiftieth to one-twentieth of an inch thick, and in masses as much as 4 inches acrose. 
Case 13.-Aged. Length of fetus, 20 inches. Uterine seal at internal os lemoncolored, elongated, ratged, and apprarently mixed with muco-pus. Pressure ou cerrix caused oozing of yellowish exulate into uterine cavity. Uterine seal at os externum apparently somewhat softened, but otherwise normal.

Vtero-chorionic space radiating from internal os contains a considerable amount of a thin, yellowish, puriform exudate.

Case 14.-Aged. Fetus full term. The uterine seal was normal, or slightly softened. Externally the uterus appeared normal. The eutire utero-chorionic eavity of the gravid horn was covered with a layer of chocolate-colored, gluey exudate, so abundant and firm that the uterine mucosa and exterior of the chorion seemed firmly glued together between the cotyledons.

For a few square inches at the internal os the exudate is mixed with tenacious masses resembling thick, viscid pus. Similur masses to the extent of 2 to 3 ounces were in the nongravil horn, and it is quite possible that the puslike masses about the internal os emanated from the nongravid horn.

As usual, the exudite appeared largely chustered about the cotyledonal stalks, not because formed there, perhaps, but rather owing to the tendency of the cotyledons to push the uterus and chorion apart at these points and thus form room in which the exudate would tend to accumulate.

The chorion was edematous, 1 inch thick, especially in the nongravid horn.

The placentik were readily delachable. The peripheral chorionic tufts were pale, anemic, ajparently necrotic, while the deeper fufts were vascular and normal. This variation in color of chorionic tufts is essentially universal, if not normal.

Case 15.-Aged. Fetus full term. Uterine seal normal. The utero-chorionic space was filled throughout its entire area with a dark chocolate-colored gluey exuclate, which was so adherive that the separation of the chorion from the uterine mucosa required some force. Detaching the chorion from the uterus, the opposing surfaces, when macroscopically cleared of the exudate, remained sticky to the touch. The exulate was more unifurmly distributed than observed in most cases, and disposed in a practically continuous sheet throughout the utero-chorionic cavity, thicker, as usual, about the cotyledonal stalks.

The uterine mucosa and uterine surface of the chorion were pinkish in color, and showed no marked discoloration, thickening, or other pathological changes,

The fetus, fetal fluids, amnion, and allantois appeared wholly normal.

The placental attarhments wre as usual, the placentis readily detachable. At the periphery, as is usual, some of the chorionic tufts were withdrawn from the uterine crypts and were consequently blanched, dirty-gray in color, and soft.

Case 16.- Two-year-old. Length of fetus, $9 \frac{1}{2}$ inches. Uterine seal normal.

The fetal sac of the nongravid horn and of the uterine body about the internal os was necrotic.

The sac of the nongravid hom was 13 inches long, devoid of cotyledons, desiccated, yellow, flattened to one-eighth of an inch thick, twisted spirally. It lay wholly free in the horn cavity, surrounded by a dirty, viscid, yellowish-brown tough exudate, estimated at 1 ounce.

The utero-chorionic space of the gravid horn contained exudate for a distance of 6 inches from the internal os. The uterine mucosa over the involved area was pale yellowish, thickened, and roughened.

Case $17,-$ Aged. Fetus 38 inches long. Uterine seal intact.

Radiating from the internal os for a distance of 12 inches, the utero-chorionic cavity was filled with a brownish-yellow, very viscid pus-like exudate one-eighth to onefourth of an inch in diameter. The fetus, amnion, and allantois were normal.

Case 18.-Aged. Length of fetus, 28 inches. Uterine seal intact.

Typical abortion exudate over entire utero-chorionic cavity. Exudate reddishbrown or light chocolate in color, in masses 1 by one-sixteenth inch, tough, sticky. 
Case 19.-Aged. Length of fetus, 9 inches. Uterine seal destroyed and cervical canal dilated.

Exterior of uterus pale yellow, the walls three-eighth of an inch thick, edematous, from which the chorion was completely detached, macerated, and very fragile. Faintly sweetish odor. Utero-chorionic space filled with a thin liquid in which floated dirty-gray flocculent masses and some viscid mucus.

The fetal membranes were edematous and brownish-green.

C'otyledons I to 2 inches, scarlet, necrotic, and readily detachable from their stalks.

Case 20.-Aged. Length of fetus, 11 inches. Uterine seal intact.

Radiating from the internal os for 12 inches in the utero-chorionic cavity is a dirty yellowish-gray sticky exudate. Uterine mucosa injected, submucous petechire. The uterine walls at the apex of the gravid horn are one-half inch thick and very edematous.

Case 21.-Aged. Fetus 38 inches long. Uterine seal unbroken.

Exudate commences about 6 inches from the os uteri internum and extends to within 12 inches of apex of comua, completely encircling it. The internal os is surrounded by thickly diffuse placenta showing abundant inter-placental hemorrhages. Apparently the diffuse placenta and close apposition of uterus and chorion explain the absence of the exudate at this point.

The exudate is chestnut-colored, very tough, and sticky. It is collected most prominently about the cotyledonal stalks, in masses often one-half inch wide by one thirty-second to one-sixteenth inch thick. Purtions of exudate lie free in cavity.

Case 22.-Aged. Fetus 36 inches long. Uterine seal intact.

Radiating from the internal os for a distance of $S$ to 10 inches is a small amount of very sticky, tough, chocolate-colored exudate. Lesser quantities are observed near the apex of the gravid cornu.

The findings of Bang, McFadyean, and Stockman, along with those recorded above, seem to justify the conclusion that the abortion exudate is an essential and universal phenomonon in contagious abortion. It does not show that the presence of the abortion exudate in any stated amount must bo followed by abortion, but rather that its presence imperils the life of the fetus.

\section{AVENUE OF INFECTION.}

The two natural avenues of infection suggested for cattle abortion are the genital tube and the alimentary canal. MeFadyean and Stockman, and to a lesser degree Bang, consider the alimentary tract the chief arenue of infection and submit experimental evidence in which animals so exposed have aborted, or, having been killed while yet pregnant, have revealed the exudate and bacilli in the utero-chorionic cavity. They have not shown conclusively that other means of infection were eliminated. Ordinarily the experimenter could not know that the Bacillus abortus was not already in the utero-chorionic carity or could not invale it through other arenues.

The infection by ingestion, as well as the experimental methods of intravenous and hypodermic inoculations, assume that the infection enters the blood and finally reaches the utero-chorionic space. But the supposed pathway by which the infection thus gains the uterochorionic cavity is not stated. Presumably under this hypothesis 
the infection must pass from the blood either through the placental filter or through the inter-cotyledonal uterine mucosa.

To the hypothesis that the infection enters through the placental filter is opposed the size of the Bang organism, which is about that of the bacillus of tuberculosis, an organism which is not known to pass the placental filter. The failure of the Bacillus abortus to pass the placental filter is further evidenced by the investigations of McFidyean and Stockman, which show that the infection appears first in the utero-chorionic space, secondly in the the fetal fluids and the fetal alimentary canal, and lastly in the fetal blood, in reverse order to what we should expect under this hypothesis.

If the infection be introduced into the blood to escape into the utero-chorionic space through the intercotyledonal mucosa, wo would expect the invasion to occur indifferently at any, and perhaps multiple points. A study of the location of the recorded lesions on pages $44-47$ denies this.

Originally Bang held that the genital canal was the arenue of infection, in which case any phenomena resulting from the invision should normally begin at the internal os and radiate therefrom forward. This is precisely what occurs with great uniformity. No recorded case presents evidence to the contrary.

It has been noted on page 23 that the uterine cavity normally becomes hermetically sealed when the embryo is one-half inch in length. The state of the uterine seal was closely observed, especially for any indications of changes from bacterial invasion. At no time when the uterine carity was healthy were we able to note any sign of injury, mechanical or bacterial, to its outer or raginal end nor in its central portion, regardless of the presence of muco-pus in the Vagina, or of well-marked chronic raginitis or other lesions, but in those cases where the fetus had died prior to the slaughter of the mother the uterine seal showed more or less complete disintegration. When the abortion exudate was present, the uterine end of the seal was stained, softened, and undergoing solution. Ita ppears to us, therefore, that the infection of contagious abortion not only enters the uterine carity through the cervical canal, but precedes the formation of the uterine seal. We believe that as a rule the infection is present in the genital tract in cows and in rirgin heifers prior to breeding.

Six 3-year-old heifers were subjected by us to an experiment. Three had ealved once each; the other three were rirgin heifers. For a few weeks prior to breeding, the genitalia of the six heifers and the bull were washed occasionally. After breeding, each receired in the jugular vein rigorous cultures of the Bang abortion bacillus, with the following results: 
1. First pregnancy. Bred May 5, 1911. Inoculated July 6, 1911 (10 c. c. in the jugular vein). Killed January 3, 1912. Uterine seal intact. Maternal and fetal membranes clean and normal. Abortion organism not found.

2. First pregnancy. Bred April 20, 1911. Inoculated July 6, 1911 (10 c. c. in the jugular vein). Killed November 14, 1911. Over the placenta from the internal os anteriorly for a distance of 10 inches there was a yellowish-white, nonodorous, pasty substance that adhered closely to the placental membrane. This substance was also found in thick rings immediately surrounding the cotyledons. The cotyledons wero scarlet. Abortion organism found.

3. First pregnancy. Bred April 14, 1911. Inoculated July 6, 1911 (10 c. c. in the jugular vein). Killed October 25, 1911. All fetal and maternal structures appeared clean and normal. Abortion organism not found.

4. Second pregnancy. Innculated January 30,1911 (20 c. c. in the jugular vein). Killed August 10, 192 days after inoculation. Uterine seal intact; chorion, uterus, fetal membranes, and fetus normal; chorionic cavity empty. No abortion bacilli recognized microscopically or culturally.

5. Second pregnancy. Inoculated July 6,1911 (7 c. c. in the jugular vein). Died August 2, 1911, of generalized tuberculosis. Fetus 5 inches in length. All fetal and genital structures appeared clean and normal.

6. Second pregnancy. Bred April 1, 1911. Inoculated July 6, 1911 (10 c. c. in the jugular vein). Killed November 6, 1911. All fetal and genital structures clean and healthy. Abortion organism not found.

It seemed that in these experiments strong oridence was brought forth to indicate that a rery cursory, intermittent washing of the vagina of the heifer, guarding the cervical canal against invasion, and of the sheath of the bull prior to breeding exerted a very marked influence upon the question of abortion. The heifers occupied the same field where five adult cows aborted, and had every opportunity to take the infection into the alimentary tract.

These and other observations compel us to believe also that if, prior to breeding, the granular venereal disease be reduced to a minimum by repeated disinfection, and the cow is then bred to a clean bull, abortion is not probable, eren with intrarenous inoculation with abortion bacilli and with ample opportunity for natural infection by the alimentary tract or otherwise.

The amount of the abortion exudate in the uterus raries widely, from the mass 1 inch across at the internal os as recorded in one case by McFadyean and Stockman, to the complete invasion of the utero-chorionic cavity, but apparently abortion follows only in rery extensive or complete invasion.

\section{THE CONTROL OF CONTAGIOUS ABORTION.}

If we accept the belief championed especially by McFadyean and Stockman, that the organisms may invade the uterus at any epoch of pregnancy or before conception, that the chief arenue of infection is the alimentary canal; that as shown by the agglutination and complement-fixation tests, the infection is in well nigh every herd; 
that the organism is present in the milk of many herds; and that raginal discharges, feces, and milk must contaminate the food of almost all cattle, the outlook for the control of abortion becomes discouraging, if not hopeless.

On the other hand, if we accept the original riew of Bang that the cervical canal is the usual arenue of invasion of the uterus, or adopt our own riew that it is essentially the sole arenue and that the inrasion must always occur prior to the sealing of the uterus, the outlook becomes somewhat more farorable, though still a formidable task.

The history of attempts to control contagious abortion is everywhere strewn with disappointment, and has opened a rich field for much of the boldest quackery every practiced upon breeders. If our views are correct, the presence of an aborting cow amongst pregnant cows can have no danger because, if the utero-chorionic space in the uteri of the pregnant animals is clean and the uterine seal is normal, any infection eliminated by the aborting animal can not reach the uterine cavity of a neighboring healthy cow. Common decency, however, in the production of milk dictates that aborted fetuses should be promptly removed in a sanitary manner and aborters having retainer placenta or vaginal discharges should be excluded from the dairy till healed, and that soiled stalls or gutters should be cleaned.

Repressive laws against contagious abortion in cattle have been proposed by various veterinarians, involving compulsory reporting of outbreaks, quarantine of infected herds, exclusion of affected animals from cattle shows, ete. So far as we know, no such laws have ever been put in force. The wide dissemination of the disease, its insidiousness, the uncertainty of its diagnosis, and other difficulties make the application of such laws impracticable.

The sale of aborting animals has been largely practiced by some breeders and dairymen. It is a wasteful and hopeless process. Our data indicate that 25 to 50 per cent of all cows ultimately abort once, so that the dispersal process is an economic waste and it fails to check abortion.

It has generally been claimed that one abortion affords a large degree of immunity. This is, according to our data, wholly erroneous. The idea that one or two abortions should confer immunity against future abortions is contrary to reason. It is the live mother and not the dead fetus which needs to be immunizcd. There is no more reason why a cow which has aborted shall thereby acquire an immunity than that one which gives birth prematurely to a calf because of the infection of contagious abortion in her uterus should become immune, or that a cow suffering from retained placenta from abortion infection, although the calf be carried full time and born healthy, should be immune. 
In one herd during a period of 10 years 61 heifers were bred on the premises for the first time, of which 3 , or 5 per cent, failed to conceive and 58 became pregnant. Among the 58 heifers in first pregnancy 21 animals, or 36 per cent, aborted or calved prematurely. Nine of the 21 aborting in first pregnaney did not conceive a second time. Ten, or $4 \mathrm{~S}$ per cent, of the heifers aborting during first pregnancy had reached, at the date of compilation, the termination of second pregnaney with two abortions (20 per cent). Thirty seven heifers calved from their first pregnancy, of which 25 (67 per ecnt) had terminated their second pregnancy at the date of compilation. Of these 25, 4 (16 per cent) aborted.

One of the four heifers which ealved from the first pregnaney and aborted from the second had retained placenta, which should be accepted as indicating that the abortion infection had then seriously invaded the pregnant uterus. Adding her to the first group of 10 heifers which aborted during first pregnancy and conceived again, we have a total of 11 , with 3 abortions, making 27 per cent of heifers aborting during first pregnancy and reaborting during second pregnancy. If we deduct this heifer from the group calving normally from the first pregnancy and aborting during the second, the total is reduced to 24 animals, of which 3 (12 per cent) aborted. In other words, the vital statistics of this herd indicate that a heifer which has aborted or given birth to a premature calf or in which calving has been complicated by retained placenta is more than twice as liable to abort during her second pregnancy as is a heifer which has calved normally from her first pregnancy.

The statement is frequently heard that after two abortions a marked immunity is acquired. Our data emplatically contradicts this. Few cows ever conceive after a second abortion. A large proportion of them succumb to metritis (placentitis with retained placenta), many fail to breed again, and many others are sold to the butcher or are otherwise excluded from the herd.

Regarding premnture birth and retained placenta as equivalents of abortion, 4 animals in the herd aborted twice or oftener. Of these 4 reaborters, one was sold after the second abortion, another was sterile for a year and then bred regularly, the third bred regularly for seven years. The fourth cow aborted her first pregnancy and had retained placenta, her second pregnancy resulted the same; she was sterile her third breeding year; gave a premature birth with retained placenta her fourth breeding rear; and a calf and retained placenta and fetal metritis in her fifth breeding year. The common belief that abortion induces immunity to future abortions is one of the most unfortunate errors which has been allowed to creep into the question of abortion in cattle. One abortion predisposes to reabortion. 
Our data show that the immunity following abortion is not the inmunity ordinarily following recovery from an acute contagious malads, but on the contrary is what we may designate age immunity. The animal has with age acquired in higher degree of resistance to abortion than she enjoyed as a heifer.

In view of the facts thus far elicited, it is doubly inexpedient to fight abortion by selling aborters. If there is truth in the belief that an animal from a herd where abortion is virulent may introduce a more highly virulent strain of infection into another herd, it is evidently wrong to sell such animals. The greatest objection to the selling plan for the control of abortion is that it causes a serious and needless drain upon the herd. Is already stated, the resistance to abortion increases with age. If an aborter will again breed, she has in the mentime aged one year, has acquired increased resistance, and is on the whole a safer breeder than the previous year. Moreover, if properly handled at the time of aborting, as Bang early pointed out, the danger from reaborting may be rery largely eliminated.

MeFadyean and Stockman and others suggest the possibility or probability of establishing an effieient immunity through the use of biological products (abortins, bacterins), but the investigations in this direction hare not yet afforded definite results. Nor can we see hope that the plan will succeed. Apparently their hopes are predicated upon an alleged natural immunity following one or two abortions. If our data are correct, the power to control abortion by this means is predicated upon our ability to induce an artificial immunity in a chronic disease incapable itself of producing natural immunity.

Sren Wall, Holth, and others have enthusiastically embraced the hypothesis that the diseaso may be controlled by isolating the infected animals with the aid of the agglutination, complement-fixation, or other laboratory tests, but a glance at their investigations intimates that a rery large percentage of animals would need to be isolated, a large proportion of herds would hare to install the method, and it is not yet determined that success would follow. The outlook at present is that the isolation would prove well-nigh as great an economic burden as the malady.

Brauer suggested many years ago the hypodermic administration of carbolic acid as a preventive for abortion, and many have had apparently good results, but there seems to be no great reason for accepting the alleged results as more than apparent.

Nueh has been claimed for vaginal disinfection of pregnant animals, but this plan has not been supported by conclusive evidence.

Our conclusion that the infection enters the uterine cavity through the ecrical canal prior to or very soon after conception leads us to advise the thorough douching of the ragina for a time before and 
immediately following breeding. It is recommended to use for this purpose warm, fecbly disinfecting solutions, such as 0.5 per cent bacterol, lysol, cresol compound, or other soapy coal-tar disinfectant. The soapy character tends beter to dissolve the mucus in the ragina and cleanse the membrane more efficiently. More reeently we have been using 0.25 or 0.5 per eent Lugol's solution, with apparently most excellent results. The solution should be introrlueed into the ragina at about the normal body temperature, $100^{\circ}$ to $105^{\circ} \mathrm{F}$. The vagina should be filled, in order that it may be fully dilated, the folds of mucosa obliterated, and the solution brought into contact with every part. It is best introduced by means of a gravity apparatus in the form of a 5-gallon ressel for medium or large herds, armed with a stopcock at the bottom, to which is attached a pure gum horso stomach tube. The ressel should then be suspended upon a manure or food track, or upon a special wire track by means of a pulley, so that it may be easily moved along behind the row of cows.

The horse stomach tube is introduced through the vulva into the vagina, and the fluid is allowed to enter the vagina by gravity.

The bull is to be handled in the same manner. The solution should be applied before and after each service by a similar, though smaller, gravity apparatus with a pure gum horse catheter for introduction into the sheath. While the fluid is passing into the sheath, the operator should prevent its escape by pressure upon the outlet until every part is well dilated and all mucous folds obliterated, so that the solution comes into contact with erery portion of the mucous membrane.

The cleansing and disinfection of the genital organs of dairy cows should hare a more important place in dairying than the precention of abortion and sterility alone. Clean milk is well-nigh impossible from cows having vulvo-vaginal discharges which soil the tail, buttocks, and thighs. With the wide distribution of the granular venereal disease, as we have pointed out, a vulvar discharge from young cows is the rule, and so uniform a rule that it is commonly regarded as normal, although such discharges are not usually observed in other domestic animals. We accordingly hold that the disinfection of the vagine of dairy cows at intervals of three or four days should be made a rule of practice by dairymen who desire to be known as producing clean milk, while our experience has amply convinced us that the plan is economically sound in keeping the cows in better health.

Immediately after cows have calved or aborted, if there be rotained placenta or uterine discharge, the uterine carity should be at once carefully disinfected and the disinfection repeated once or twice daily so long as the cervical canal is freely open, in order to overcome the infection present and thereby do all possible to prevent sterility and to avoid abortion during the next pregnancy. 
The proposed method of handling abortion and sterility is merely repressive, however important. We do not hope thereby to eliminate either abortion or the granular venereal disease from the herd, but only that we shall be able, at a justifiable cost, to reduce the losses from abortion and sterility. Accepting the infections of the genital tract as permanent, any measures against them should have a similar continuity and be accepted as one of the elements in the operation of dairying.

\section{THE PRODUCTION OF SOUND HERDS.}

Abortion and sterility are not alone in reducing the effieiency in dairying and breeding herds. In many herds similar losses occur from calf scours and pneumonia and from tuberculosis. These three great dairy scourges cause their chief devastation in the young. Scours and pneumonia destroy most of their victims during the first fewweks after birth. Abortion and sterility play their greatest havoc among cows and heifers 2 to 4 years old. Tuberculosis largely has its origin through the food of the calf, or the heifer becomes affected during her first years in the dairy. If eattle breeding and dairying are to be placed upon a more secure basis, it is first of all essential to maintain in health the new-born calves.

Calf scours and pneumonia have been sufficiently investigated that their nature is well enough known to undertake prevention with a reasonable measure of confidence. A method has been pointed out and its feasibility demonstrated whereby calves may be raised free from tubereulosis in spite of tuberculous parents. The measures adrisable for the repression and prevention of these can be made to answer in large measure for the control of abortion and sterility, and any needed additions to the sanitary measures for the control of abortion would add to the efficiency of the measures relating to the other maladies.

The maternity and calf stables of our larger dairies and more important breeding herds constitute the fundamental source of the chicf losses amongst dairy cattle. It is a notable fact that in many of our highest class, or highest classed, dairies the dairy stables are extravagantly well built, while the maternity and calf barns are disgraceful old ramshackles, more worthy of being called pest houses. The control of dairy plagues must begin and be most exact with the newborn ealf when it is most vulnerable to disease, and in large dairy and breeding establishments the proper handling of the cow at the time of parturition and the care of the newborn calf should have first place in the entire scheme.

The infections causing calf scours and pneumonia, abortion and sterility, and tuberculosis are so thoroughly disseminated that for practical purposes, with some exceptions in relation to tuberculosis, 
all cows should be regarded as suspicious and all newborn calves treated as being in danger of exposure to the infection of any or all of these dairy plagues.

While the prospect for presenting abortion (and sterility) appears quite feasible, in the present state of our knowledge we can lay down no reliable means for wholly avoiding the infection of the granular renereal disease. If we accept the hypothesis of any recorded investigator or group of inrestigators, we have as yet no more promising method of getting a herd free from abortion than by taking the newborn calf and guarding it perpetually. The plan can at most be criticized only as beginning too early, because the fight against abortion might be delayed for economic reasons until the animal has reached the age of 6 to 12 months, when, according to Bang, MfcFadyean and Stockman, and others, they may take the bacilli in their food, and the infection lie in wait until pregmaney affords fuel for a conflagration. In the meantime the isolation is needed because of scours and pneumonia and tuberculosis, and while these two are being eraded the third may be sinultaneously parried. 'The growing' of sound calves in relation to the three scourges named appeals to us as the most interesting and urgent problem before the cattle breeder. In order to accomplish results radical changes in the handling of newborn calves must be established. Maternity and calf buildings must meet fully all demands for light, air, and temperature, and to these must be added practicability of thorough cleansing.

\section{A PLAN FOR BREEDING SOUND ANIMALS.}

We would outline the following plan for the breeders of pedigreed and raluable dairy cattle with a riew to the production of cleaner and more efficient herds.

1. The construction or arrangement of independent maternity and calf nursery stables embodying all modern requirements for ventilation, light, heat, convenience for disinfection, and ample facilities for the exclusion of flies. The stables should provide sufficient indiridual stalls for all ealring cows and indiridual stalls for calves until at least three months old.

2. A cow which is about to calve should be well cleaned and her posterior parts disinfected, after which she should be placed in a clean stall some dnys prior to expected parturition. Pending parturition the stall should be kept scrupulously clean and well disinfected. The tail, rultra, buttocks, and udder should be disinfected twice daily. In order to aroid the danger of infection to the ealf while passing through the ragina of the cow during birth either by the infeetion of white scours, the granular renereal disease, or other malady, the ragina should be irrigated daily with a mild disinfoctant such as 0.5 per cent Lugol's solution. Such attention to the vagina also tends 
to carry away any infections within the vagina which immediately after the opening of the cervical canal of the uterus at the time of cal ring may otherwise drop into the uterine cavity and there establish disease.

3. When the calf is born it should be received upon a clean antiseptic sheet and at once carried to a clean calf stall and rubbed dry. If it is desired to allow the calf to remain temporarily with the cow, great care should be taken to see that the bedding is kept clean.

After the calf has been dried, if not earlier, the stump of the narel cord should be disinfected. It should not be ligated. Prepare a warm 1 to 1,000 solution of corrosive sublimate, fill a goblet or cup with it, and, having the calf held in a standing position, press the vessel against the floor of the belly so that the stump of the navel cord is submerged in the disinfeeting fluid. Retain it in this position for at least 10 minutes. Immediately afterwards dust the stump of the cord over liberally with a disinfecting desiccating powder, as alum and camphor, and repeat erery 30 minutes until the stump is dry.

The body openings (mouth, nostrils, vulva of heifer, and sheath of bull calf) should be disinfected with a 0.5 per cent Lugol's solution.

4. Prior to drawing milk from the dam or other cow for feeding the calf, or permitting the calf to suck, the udder and adjacent parts of the cow should be thoroughly disinfected. The milk should be drawn in a sterile vessel under the strictest cleanliness. If the milk is from a cow not known to be free from tuberculosis, it should be sterilized before feeding. Individual feeding vessels should be used and regularly sterilized.

When calves have reached 3 months of age, it may usually be fairly determined if they are free from disease, in which case they may be handled in groups. These, however, should be kept as small as economically practicable until the heifers have calved and are ready for the dairy. Even then the larger the number of animals in one stable the greater the risk of infection and the more destructive will it be if it gains entrance.

5. When breeding time for the heifer grown under the foregoing conditions is approaching, we would advise that her vagina bo douched once daily for at least three weeks before breeding, at first with a 0.5 per cent Lugol's solution, and thereafter each second day with a 0.25 per cent solution. The douching should extend over at least one estrual period, or 21 days prior to breeding, and followed for an equal time after breeding, or until it is determined she is pregnant. The bull should preferably have been grown in the same manner as the heifers he is to serve and his genitals douched in a similar way. 


\section{CONCLUSIONS.}

1. Abortion in cattle is essentially always the result of a chronic infection within the utero-chorionic space, revealing itself postmortem by the presence of the so-called abortion exudate, which contains generally, if not always, the abortion bacilli.

2. The granular venereal disease of cattle is, so far as known, universally distributed. From elinical observation it has a vital relation to contagious abortion. It is incurable in the present state of our knowledge, but may be greatly decreased in virulence.

3 . Contagious abortion of cattle has attained an essentially universal distribution, frequently present merely as an unrecognized infection of the genital organs, not inducing actual abortion but causing premature birth, retained afterbirth, and sterility.

4. The ordinary if not sole avenue of the entrance of the infection of contagious abortion is the genital canal, and the invasion antedates the sealing of the uterus, which ordinarily occurs within 30 days after conception.

5. When conception has occurred and the cervical canal has been sealed, the fate of the fetus is settled. If a sufficiently virulent and voluminous infection exists in the utero-chorionic space, abortion may result; if such infection does not exist within the sealed uterochorionic space when the formation of tho seal is completed, it will not enter thereafter during pregnancy.

6. In the present state of our knowledge little or nothing can be done to prevent abortion once the pregnant uterus is sealed and the infection of contagious abortion exists within the hermetically sealed cavity.

7. By systematic disinfection of the genitalia immediately following abortion or premature birth, and also in retained afterbirth and kindred infections of the uterus, the affected animals may be largely guarded against future sterility and abortion. It is even more important that the vagina of heifers, whether virgin or previously bred, and cows shall be systematically disinfected for a period before and after breeding, until conception is assured.

8. It is equally important that the genital organs of breeding bulls be kept clean by regular disinfection, including washing immediately prior to and after service.

9. Most important of all, breeders of valuable cattle should institute definite, energetic, and permanent efforts to guard new-born calves simultaneously against the three great dairy scourges-calf scours and pneumonia, abortion and sterility, and tuberculosis. 
ADDITIONAL COPIES

OP THIS PUBLICATION MAY BE PROCURED FROM THE SUPERINTENDENT OF DOCUMFNTS

GOVERNMENT PRINTING OFFICE

WASHINGTON, D, C.

AT

$\nabla$ 



Makers Syracuse, N. Y PAT. JAN. 21, 1908 


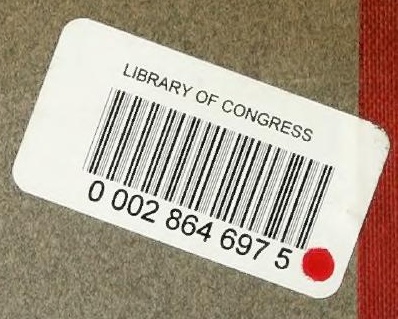

